Supporting information

\title{
Development of biphenylthiazoles exhibiting improved pharmacokinetics and potent activity against intracellular Staphylococcus aureus
}

Mohamed Hagras ${ }^{1 \|}$, Nader S. Abutaleb ${ }^{2 \Perp}$, Noha M. Elhosseiny, ${ }^{3}$ Tamer M. Abdelghany, ${ }^{4}$ Mariam Omara, ${ }^{4}$ Mohamed M. Elsebaei ${ }^{1}$, Marwa Alhashimi ${ }^{2}$, Allison B Norvil ${ }^{5}$, Mark I Gutay ${ }^{5}$, Humaira Gowher ${ }^{5,6}$, Ahmed S. Attia, ${ }^{3}$ Mohamed N. Seleem ${ }^{2,7^{*}}$ and Abdelrahman S. Mayhoub ${ }^{1,8^{*}}$

${ }^{1}$ Department of Pharmaceutical Organic Chemistry, College of Pharmacy, Al-Azhar University, 1-Elmokhayem Eldaem Street, Cairo 11884, Egypt.

${ }^{2}$ Department of Comparative Pathobiology, College of Veterinary Medicine, Purdue University, 725 Harrison Street, West Lafayette, IN 47907, USA.

${ }^{3}$ Department of Microbiology and Immunology, Faculty of Pharmacy, Cairo University, Cairo, Egypt, 11562.

${ }^{4}$ Department of Pharmacology and Toxicology, College of Pharmacy, Al-Azhar University, 1Elmokhayem Eldaem Street, Cairo 11884, Egypt.

${ }^{5}$ Department of Biochemistry, College of Agriculture, Purdue University, West Lafayette, IN 47907, USA.

${ }^{6}$ Purdue University Center for Cancer Research, Purdue University, West Lafayette, IN 47907, USA

${ }^{7}$ Department of Biomedical Sciences and Pathobiology, Virginia-Maryland College of Veterinary Medicine, Virginia Polytechnic Institute and State University, Blacksburg, VA, 24061, USA.

${ }^{8}$ University of Science and Technology, Nanoscience Program, Zewail City of Science and Technology, Ahmed Zewail Street, October Gardens, $6^{\text {th }}$ of October, Giza 12578, Egypt

Corresponding Authors.*e-mail: mseleem@purdue.edu, amayhoub@azhar.edu.eg

"These two authors contributed equally 


\section{Contents}

Figure S1

S3

Methods

In vitro cytotoxicity assessment of compounds 16 and 19 against J774 cells

S3

Intracellular infection of J774 cells with MRSA

S4

In vitro cytotoxicity evaluation against Caco-2, $\mathrm{HaCaT}$ and $\mathrm{J} 774$ cells

S4

MICs and MBCs of tested compounds against Staphylococcus aureus and important Gram-

positive bacterial pathogens

S5

Human Microsomal Stability Analysis

S6

NMR spectra

S7 


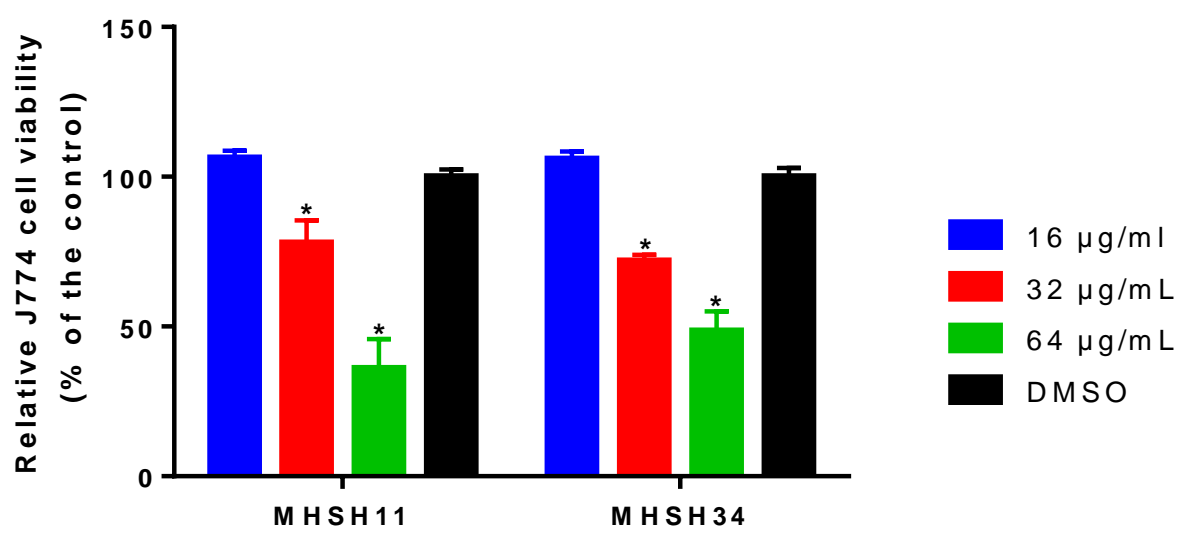

Figure S1. Toxicity analysis of compounds 16 and 19 against murine macrophage (J774) cells using the MTS 3-(4,5-dimethylthiazol-2-yl)-5-(3-carboxymethoxyphenyl)-2-(4-sulfophenyl)-2Htetrazolium) assay. Results are presented as percent viable mammalian cells (measured as average absorbance ratio relative to DMSO). The absorbance values represent an average of a minimum of three samples analyzed for each compound. Error bars represent standard deviation values for the absorbance values. Data were analyzed via a two-way ANOVA with post hoc Dunnett's test for multiple comparisons. Asterisks $(*)$ denote a statistical difference $(\mathrm{P}<0.05)$ between values obtained for the compounds and the DMSO.

\section{Methods}

In vitro cytotoxicity assessment of compounds 16 and 19 against $\mathbf{J 7 7 4}$ cells. Tested compounds were assayed against a murine macrophage (J774) cell line to determine their in vitro potential toxic effect. Cells were cultured in Dulbecco's Modified Eagle Medium (DMEM) supplemented with $10 \% \mathrm{FBS}$ at $37{ }^{\circ} \mathrm{C}$ with $5 \% \mathrm{CO}_{2}$. Control cells received DMSO alone at a concentration equal to that in drug-treated cell samples. The cells were incubated with the compounds (in triplicate) in a 96-well plate at $37^{\circ} \mathrm{C}$ with $5 \% \mathrm{CO}_{2}$ for 24 hours. The assay reagent MTS;3-(4,5-dimethylthiazol2-yl)-5-(3-carboxymethoxyphenyl)-2-(4-sulfophenyl)-2H-tetrazolium) (Promega, Madison, WI, USA) was subsequently added and the plate was incubated for four hours. Absorbance readings (at $\mathrm{OD}_{490}$ ) were recorded using a kinetic microplate reader (Molecular Devices, Sunnyvale, CA, USA). The quantity of viable cells after treatment with each compound was expressed as a 
percentage of the viability relative to DMSO-treated control cells (average of triplicate wells \pm standard deviation).

Intracellular infection of J774 cells with MRSA and treatment with compounds 16 and 19. Murine macrophage cells (J774) were cultured in Dulbecco's Modified Eagle Medium (DMEM) supplemented with $10 \% \mathrm{FBS}$ at $37^{\circ} \mathrm{C}$ with $\mathrm{CO}_{2}(5 \%)$. $\mathrm{J} 774$ cells were exposed to MRSA USA400 cells at a multiplicity of infection of approximately 10:1. After 1 hour of infection, J774 cells were washed with gentamicin $(200 \mu \mathrm{g} / \mathrm{mL})$ to kill extracellular MRSA. The compounds or vancomycin (at $4 \times$ MIC) were subsequently added to each well (four replicates per test agent). Control cells received DMSO at a concentration equal to that in drug-treated cell samples. After 24 hoursincubation at $37^{\circ} \mathrm{C}$ with $5 \% \mathrm{CO}_{2}$, the test agents were removed. $\mathrm{J} 774$ cells were washed and subsequently lysed using $0.1 \%$ Triton-X. The solution was serially diluted in phosphate-buffered saline and transferred to TSA plates in order to determine viable MRSA CFU inside the J774 cells. Plates were incubated at $37^{\circ} \mathrm{C}$ for $18-22$ hour before counting viable $\mathrm{CFU} / \mathrm{mL}$. Statistical significance was assessed with two-way ANOVA, with post hoc Dunnet's multiple comparisons test $(\mathrm{P}<0.05)$, utilizing GraphPad Prism 6.0 (GraphPad Software, La Jolla, CA)

In vitro cytotoxicity evaluation against Caco-2, HaCaT and $\mathbf{J 7 7 4}$ cells. Tested compounds were assayed, as described in previous reports, ${ }^{1}$ against a human colorectal (Caco-2), human keratinocytes (HaCaT) and murine macrophage (J774) cells to determine the potential toxic effect to mammalian cells. Briefly, Caco-2 cells were cultured in Dulbecco's Modified Eagle Medium (DMEM) supplemented with 20\% fetal bovine serum (FBS), non-essential amino acids (1X), penicillin-streptomycin at $37^{\circ} \mathrm{C}$ with $\mathrm{CO}_{2}(5 \%)$. $\mathrm{HaCaT}$ and $\mathrm{J} 774$ cells were cultivated in DMEM supplemented with 10\% FBS. The cells were incubated with the compounds (in triplicate) in a 96well plate at $37{ }^{\circ} \mathrm{C}$ with $5 \% \mathrm{CO}_{2}$ for 2 hours (for Caco-2 and $\mathrm{HaCaT}$ cells), or 24 hours (in case of 
J774 cells). Control cells received DMSO alone at a concentration equal to that in drug-treated cell samples. The assay reagent MTS 3-(4,5-dimethylthiazol-2-yl)-5-(3-carboxymethoxyphenyl)-2-(4sulfophenyl)-2H-tetrazolium) (Promega, Madison, WI, USA) was subsequently added. Absorbance readings were recorded using the SpectraMax i3 Multi-Mode Microplate Reader (Molecular Devices, Sunnyvale, CA). The quantity of viable cells after treatment with each compound was expressed as a percentage of the viability relative to DMSO-treated control cells (average of triplicate wells \pm standard deviation). The data were analyzed via a two-way ANOVA with post hoc Dunnett's test for multiple comparisons. Asterisks $(*)$ denote statistical difference $(\mathrm{P}<0.05)$ between the treatment with either tested compounds and DMSO.

MICs and MBCs of tested compounds against Staphylococcus aureus and important Grampositive bacterial pathogens. The minimum inhibitory concentration (MIC) of tested compounds and control antibiotics was determined using the broth microdilution method according to the guidelines outlined by the Clinical and Laboratory Standards Institute (CLSI) ${ }^{2}$. Bacterial strains were grown aerobically overnight on tryptone soy agar plates at $37^{\circ} \mathrm{C}$. Afterwards, a bacterial solution equivalent to $0.5 \mathrm{McFarland}$ standard was prepared and diluted in cation-adjusted Mueller-Hinton broth (CAMHB) to achieve a bacterial concentration of about $5 \times 10^{5} \mathrm{CFU} / \mathrm{mL}$ and seeded in 96-well plates. S. pneumoniae, E. faecalis, E. faecium, and L. monocytogenes strains were diluted in tryptone soy broth (TSB) to achieve a bacterial concentration of about $5 \times 10^{5}$ CFU/mL. Compounds and control drugs were added in the first row of the 96-well plates and serially diluted along the plates. Plates were then, incubated aerobically (except for S. pneumoniae strains that were incubated in presence of $5 \% \mathrm{CO}_{2}$ ) at $37^{\circ} \mathrm{C}$ for $18-20$ hours. MICs reported here are the minimum concentration of the compounds and control drugs that completely inhibited the visual growth of bacteria. The minimum bactericidal concentration (MBC) of these compounds was tested by plating $4 \mu \mathrm{L}$ from wells with no growth onto Tryptic soy agar plates. Plates were 
incubated at $37^{\circ} \mathrm{C}$ for $18-20$ hours before recording the $\mathrm{MBC}$. The $\mathrm{MBC}$ was categorized as the lowest concentration that reduced bacterial growth by $99.9 \%$.

Human Microsomal Stability Analysis. The metabolic stability of compound $\mathbf{1 6}$ to the hepatic metabolism was analyzed with pooled human liver microsomes as described previously. ${ }^{3}$ The tested compounds were incubated in duplicates with human liver microsomes (pooled from human donors) at $37^{\circ} \mathrm{C}$. The reaction contained microsomal protein in $100 \mathrm{mM}$ potassium phosphate, 2 mM NADPH, $3 \mathrm{mM} \mathrm{MgCl} 2, \mathrm{pH}$ 7.4. A control was run for each test agent omitting NADPH to detect NADPH-free degradation. At 0, 15, 30, 45, and 60 minutes, an aliquot was removed from each experimental and control reaction and mixed with an equal volume of ice-cold stop solution (methanol containing haloperidol, diclofenac, or other internal standard). Stopped reactions are incubated at least ten minutes at $-20^{\circ} \mathrm{C}$, and an additional volume of water was added. The samples were centrifuged to remove precipitated protein, and the supernatants were analyzed by LC/MS/MS to quantitate the remaining parent. Data are converted to $\%$ remaining by dividing by the time zero concentration value. Data are fit to a first-order decay model to determine half-life. Intrinsic clearance is calculated from the half-life and the protein concentrations: $C L_{i n t}=\ln (2)$ $/\left(T_{1 / 2}[\right.$ microsomal protein] $)$. 


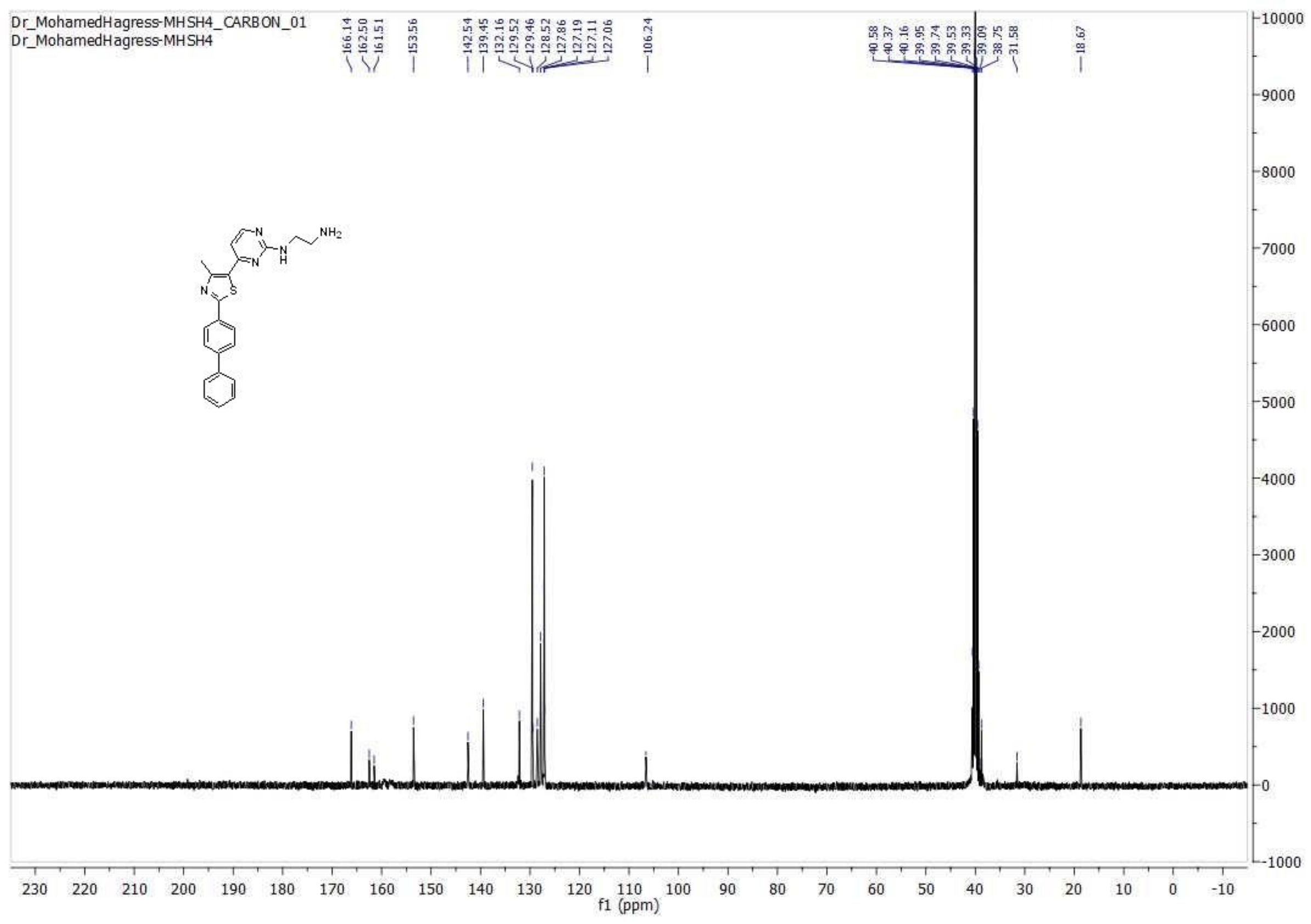




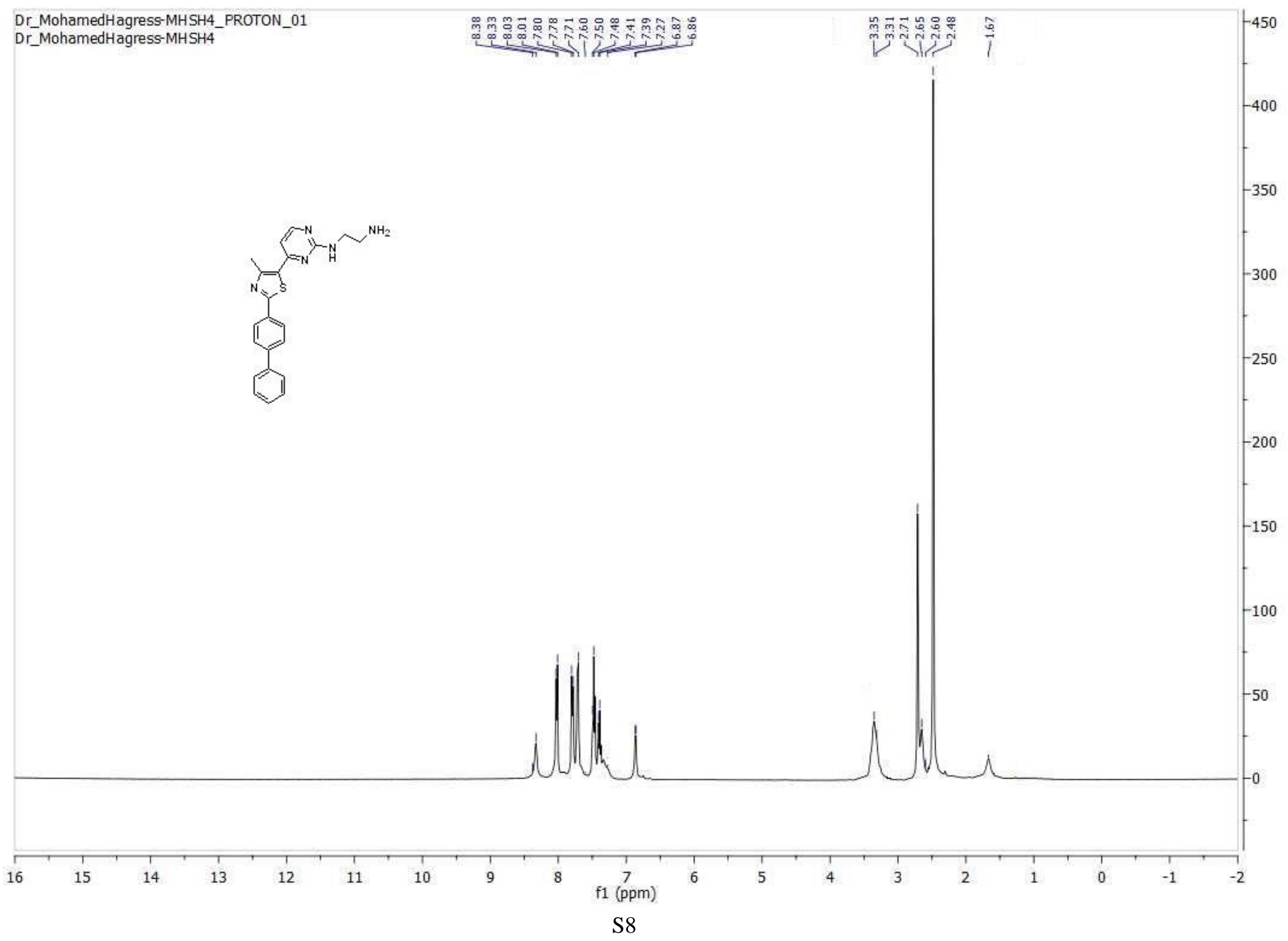




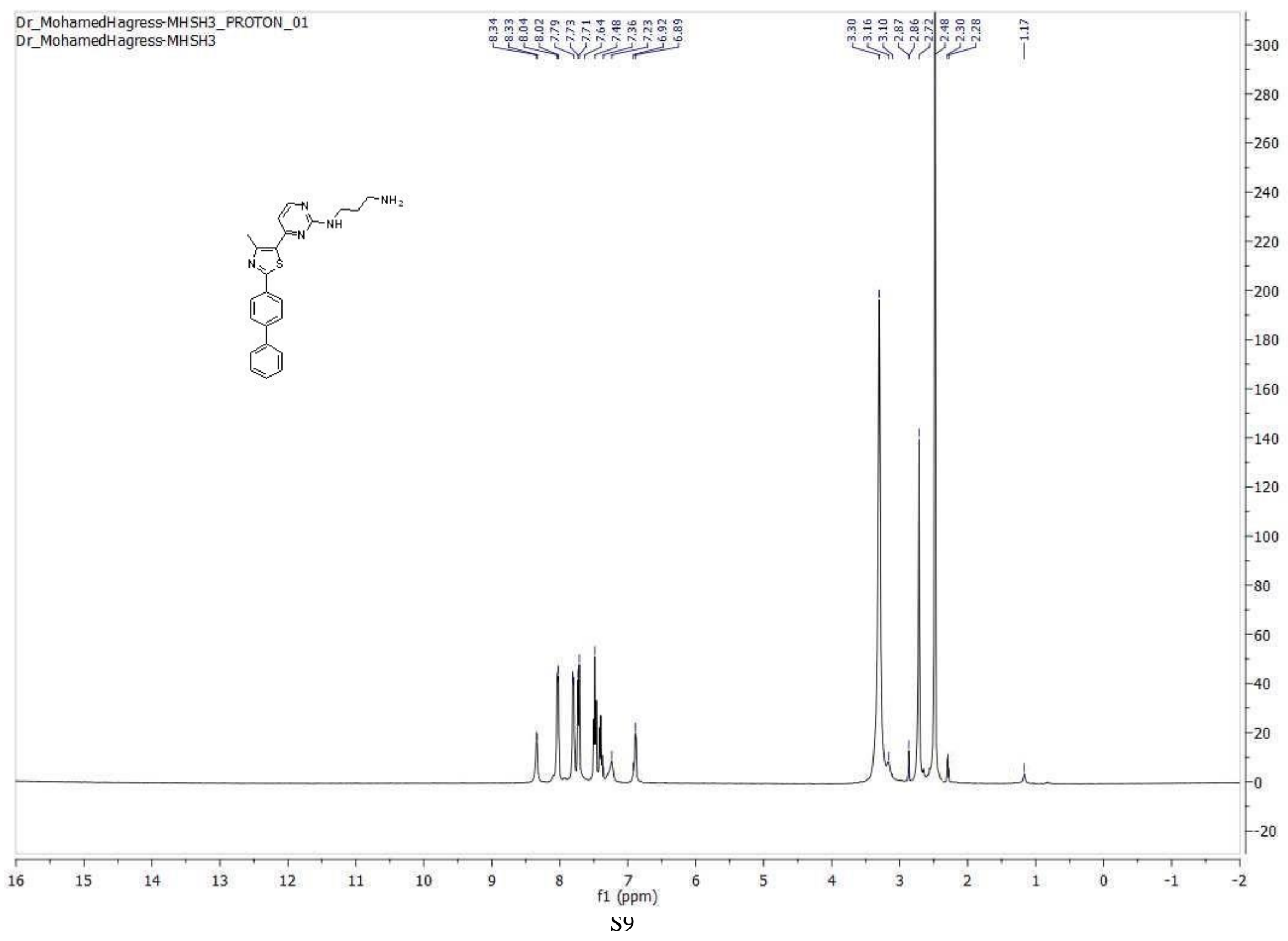




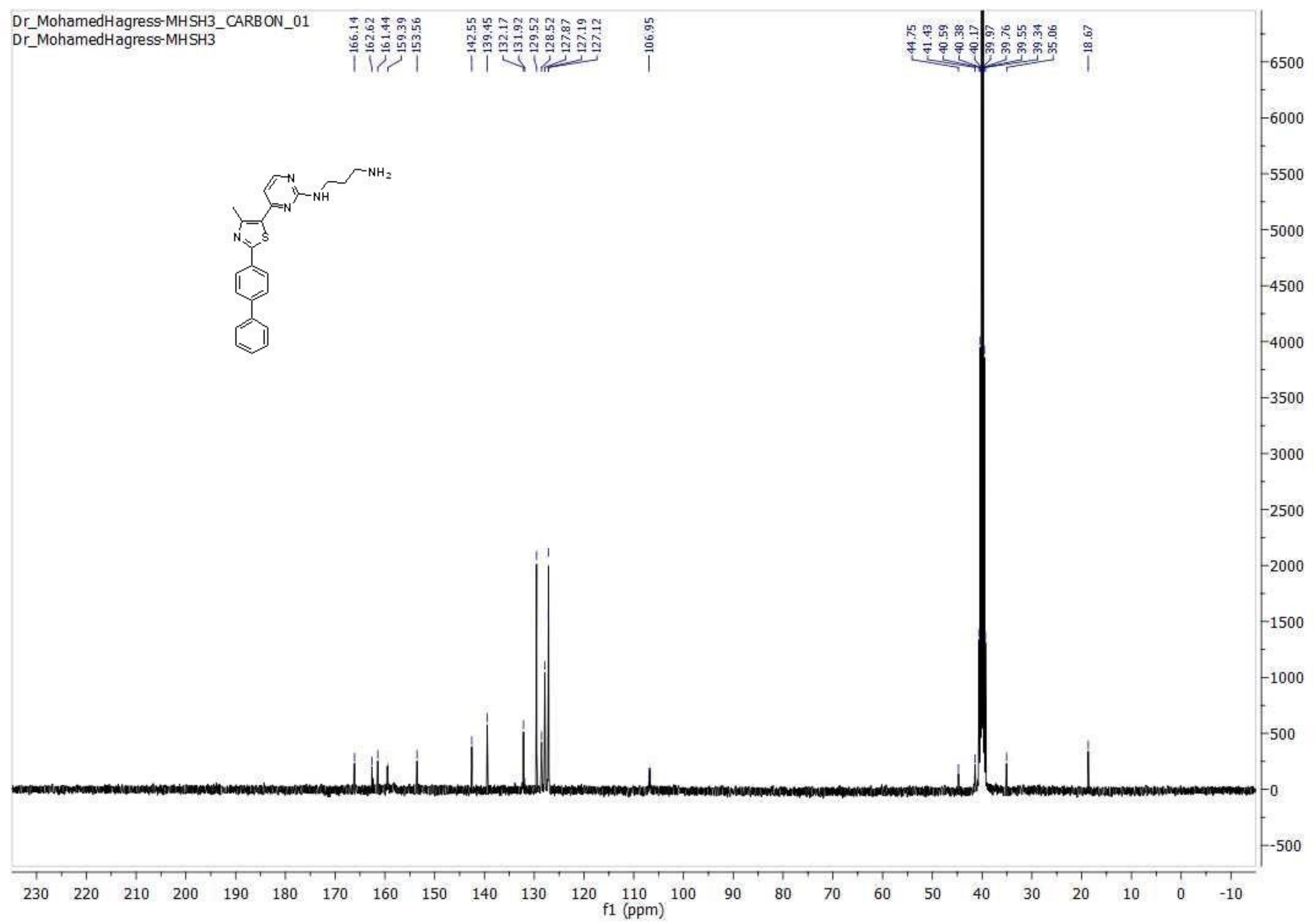




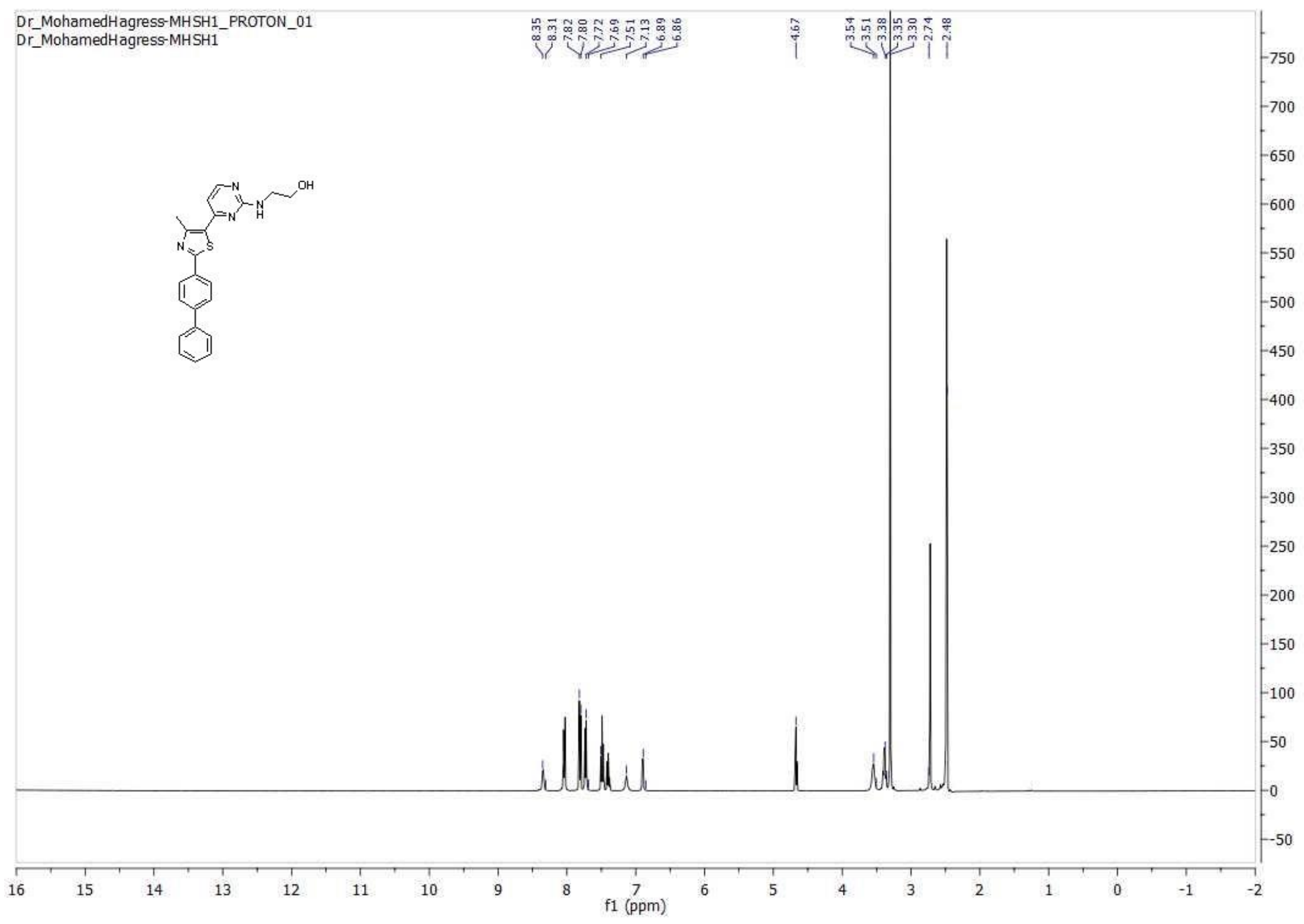




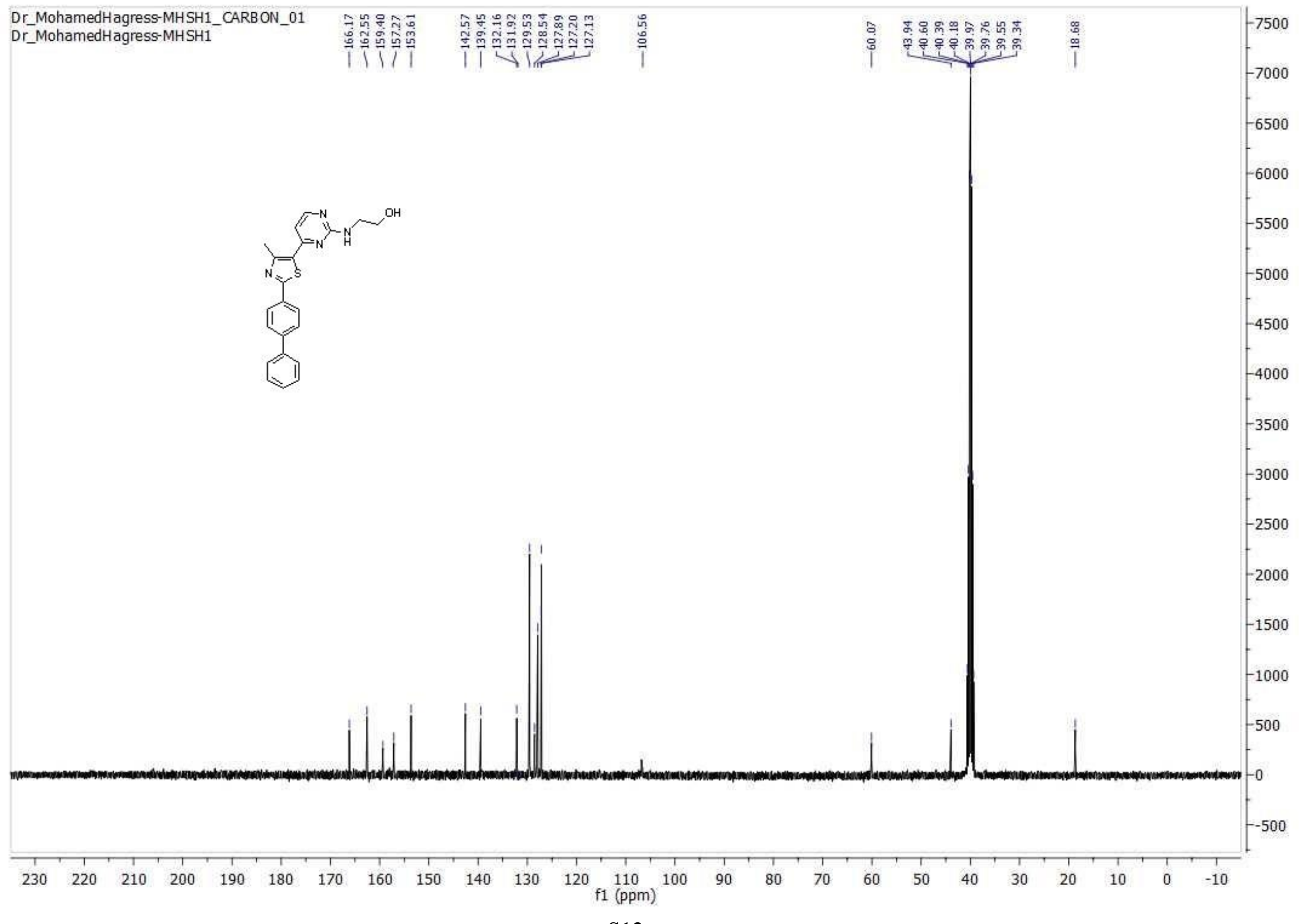

S12 


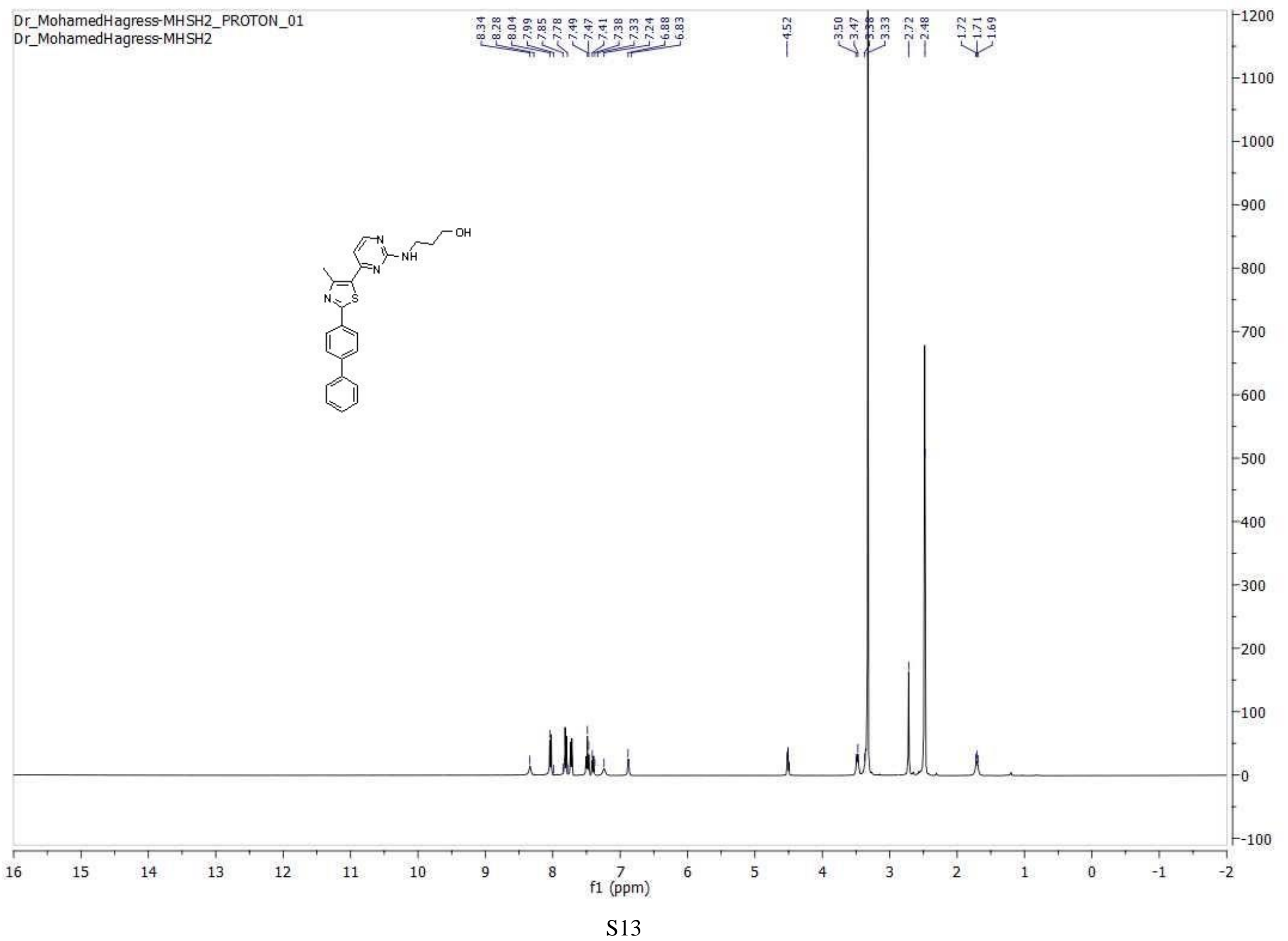




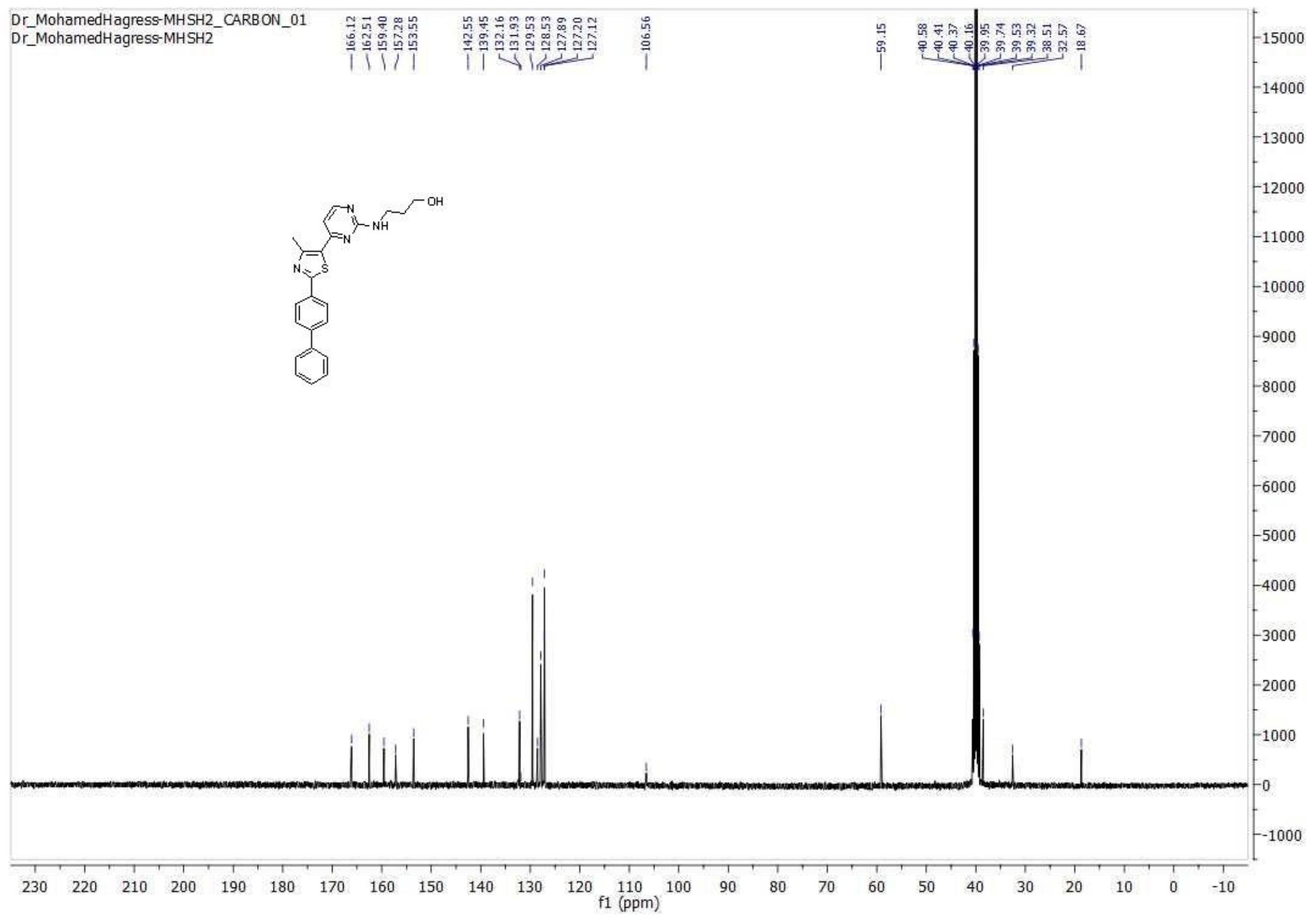




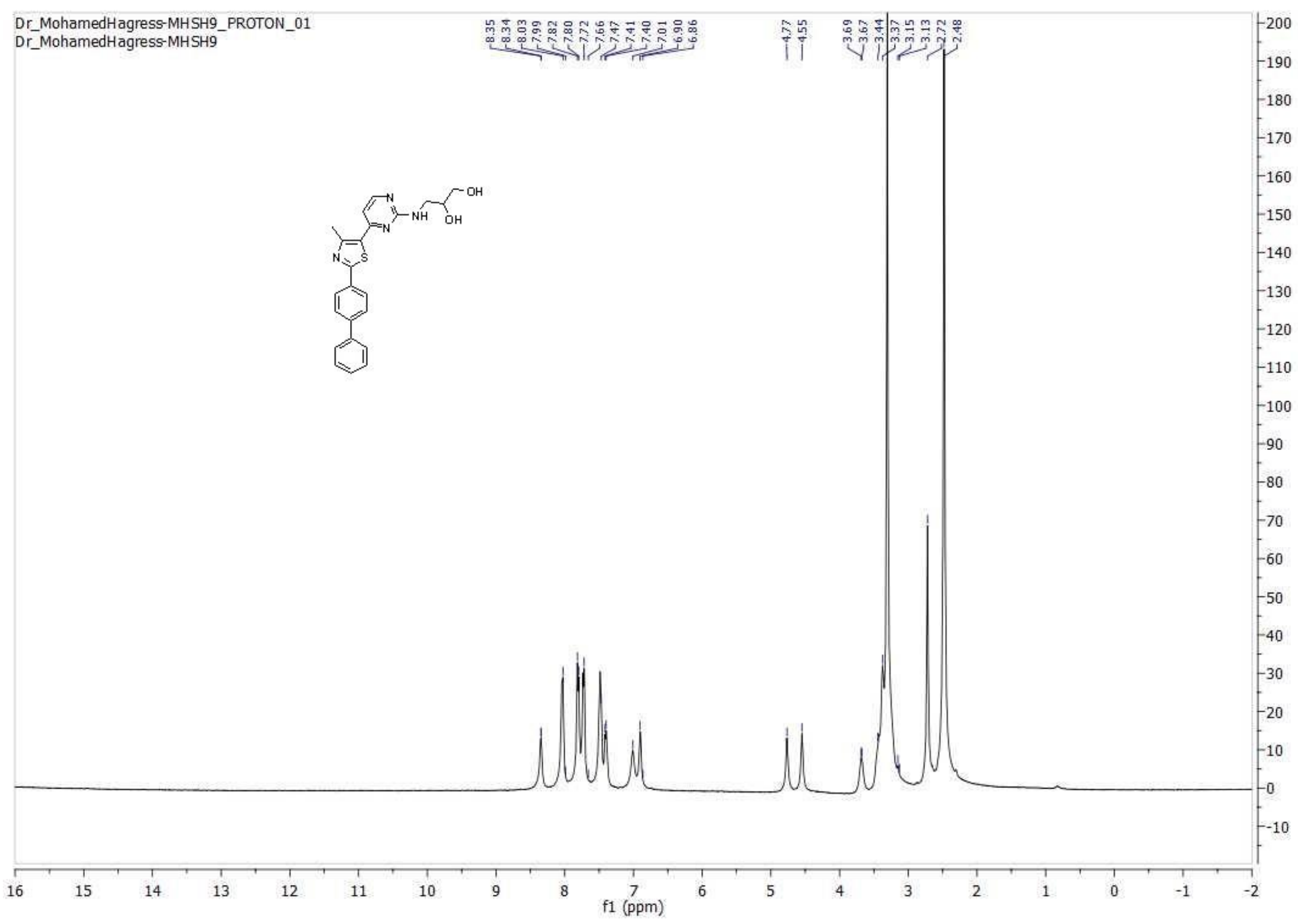




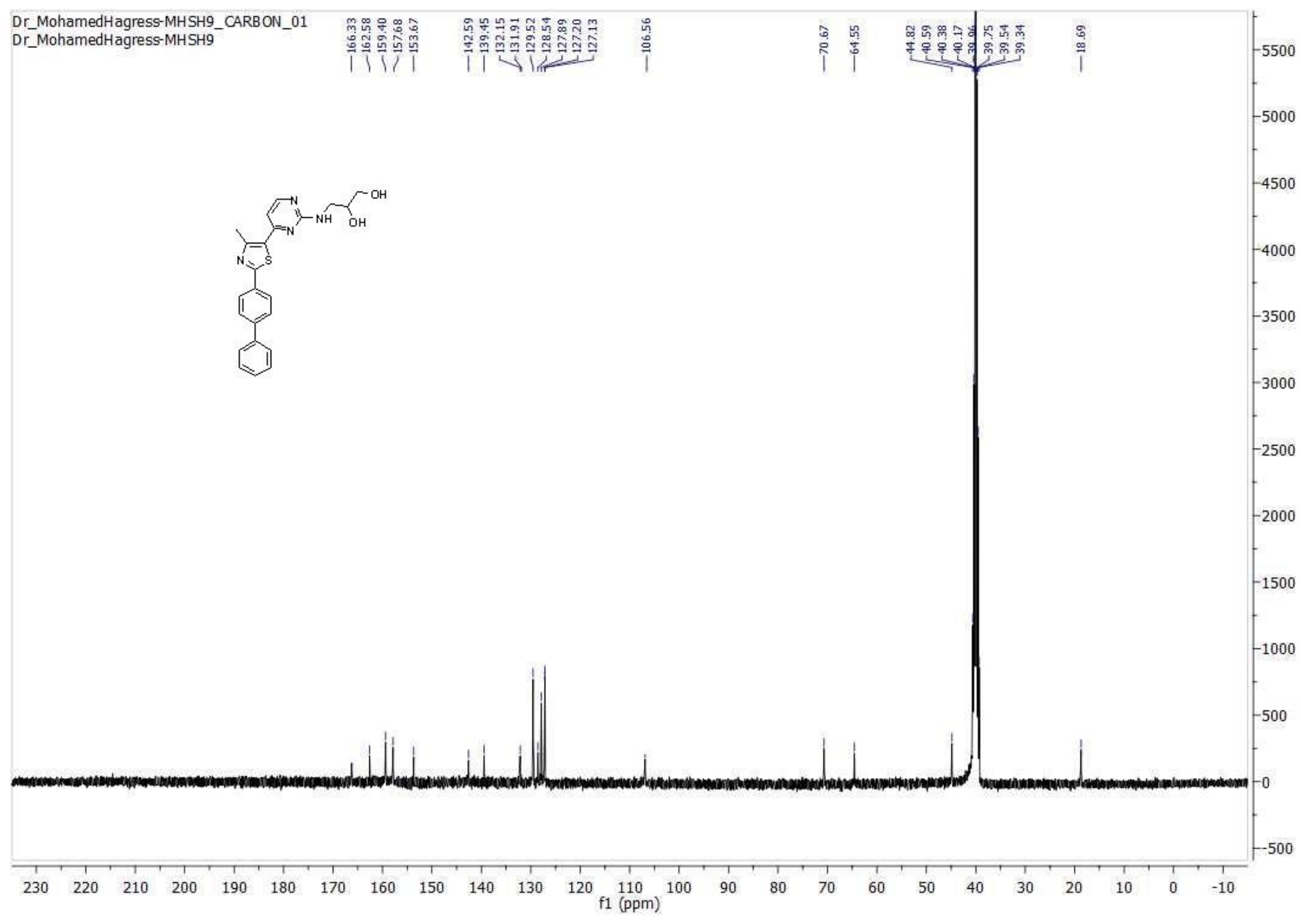

S16 


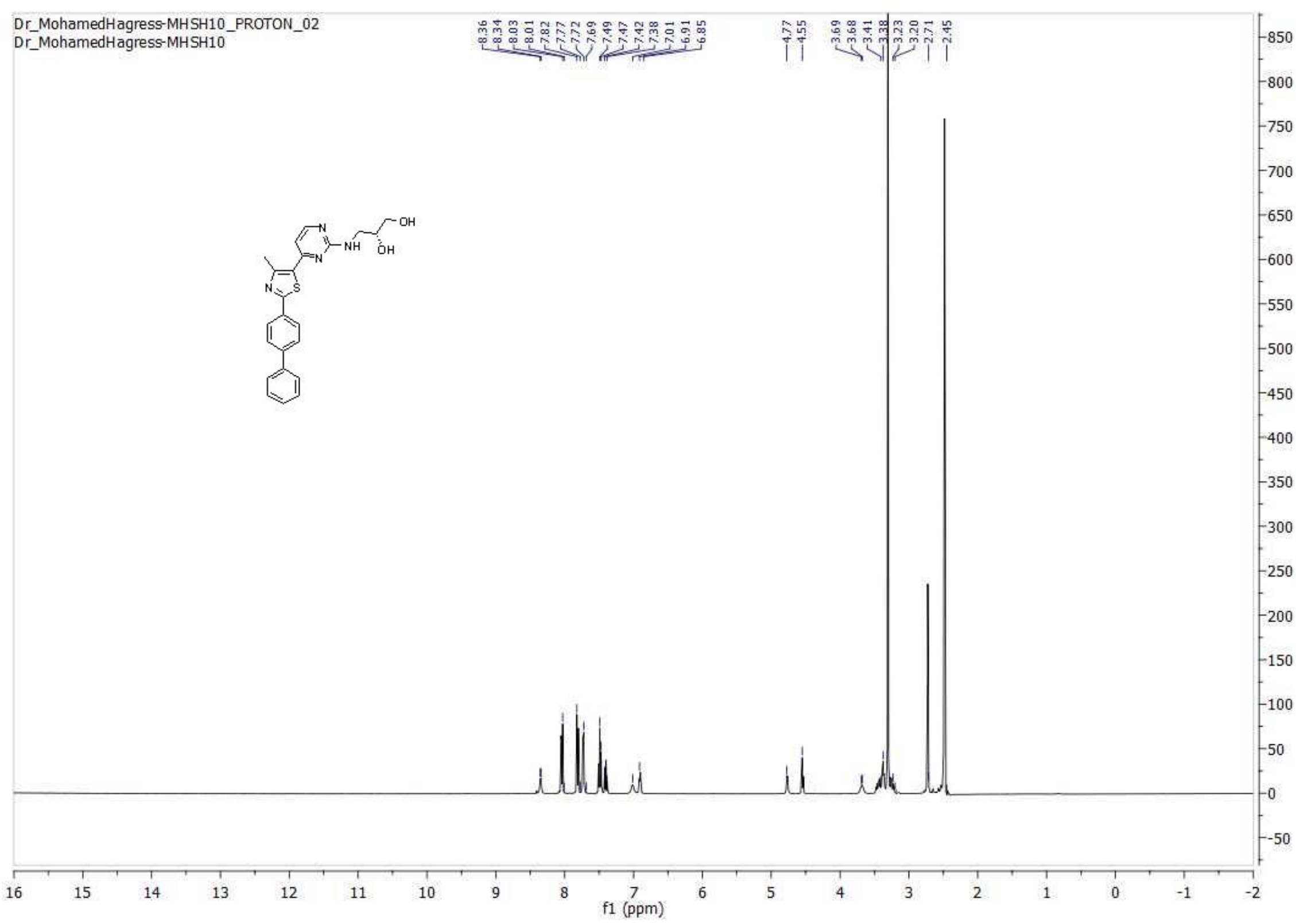




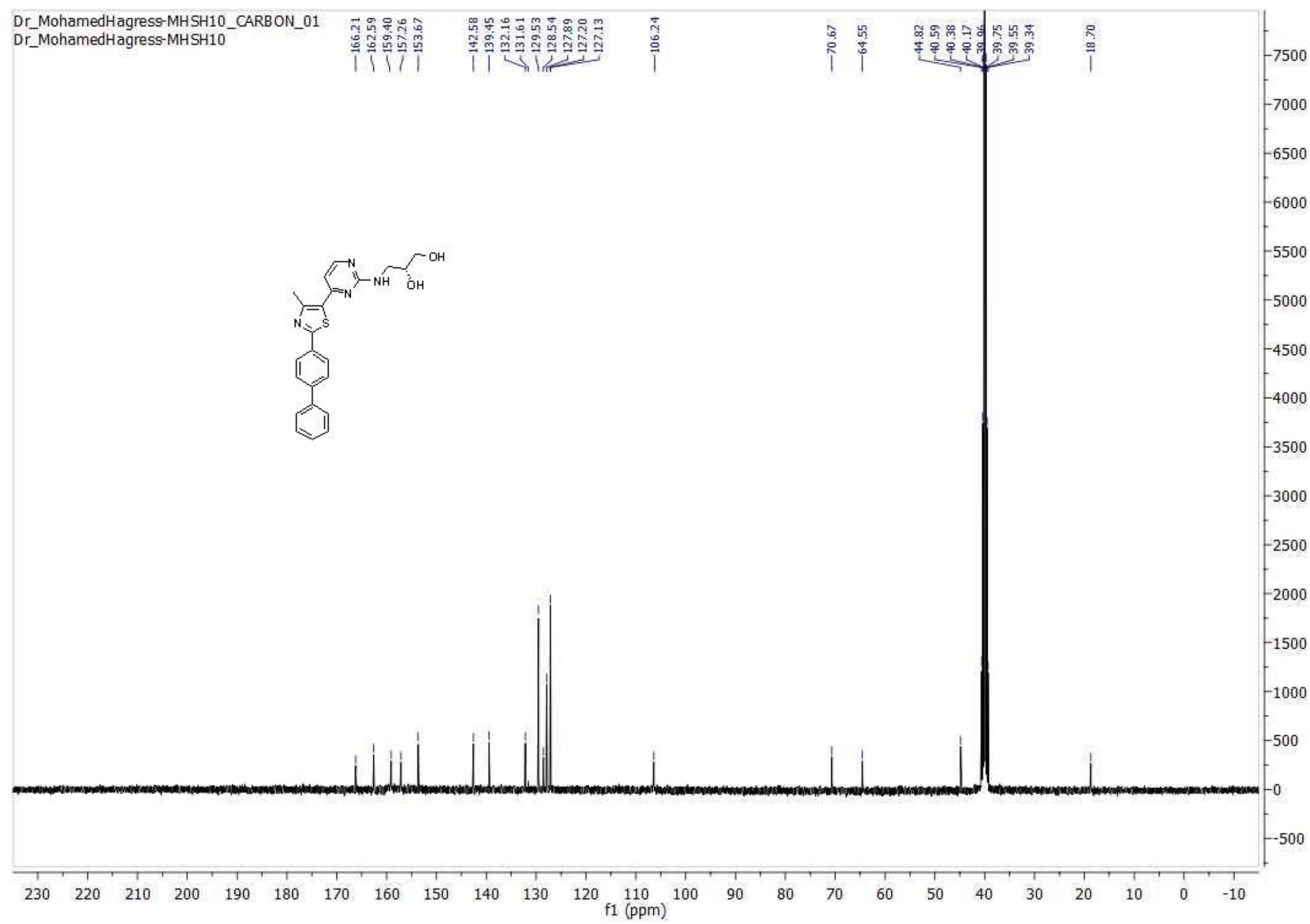




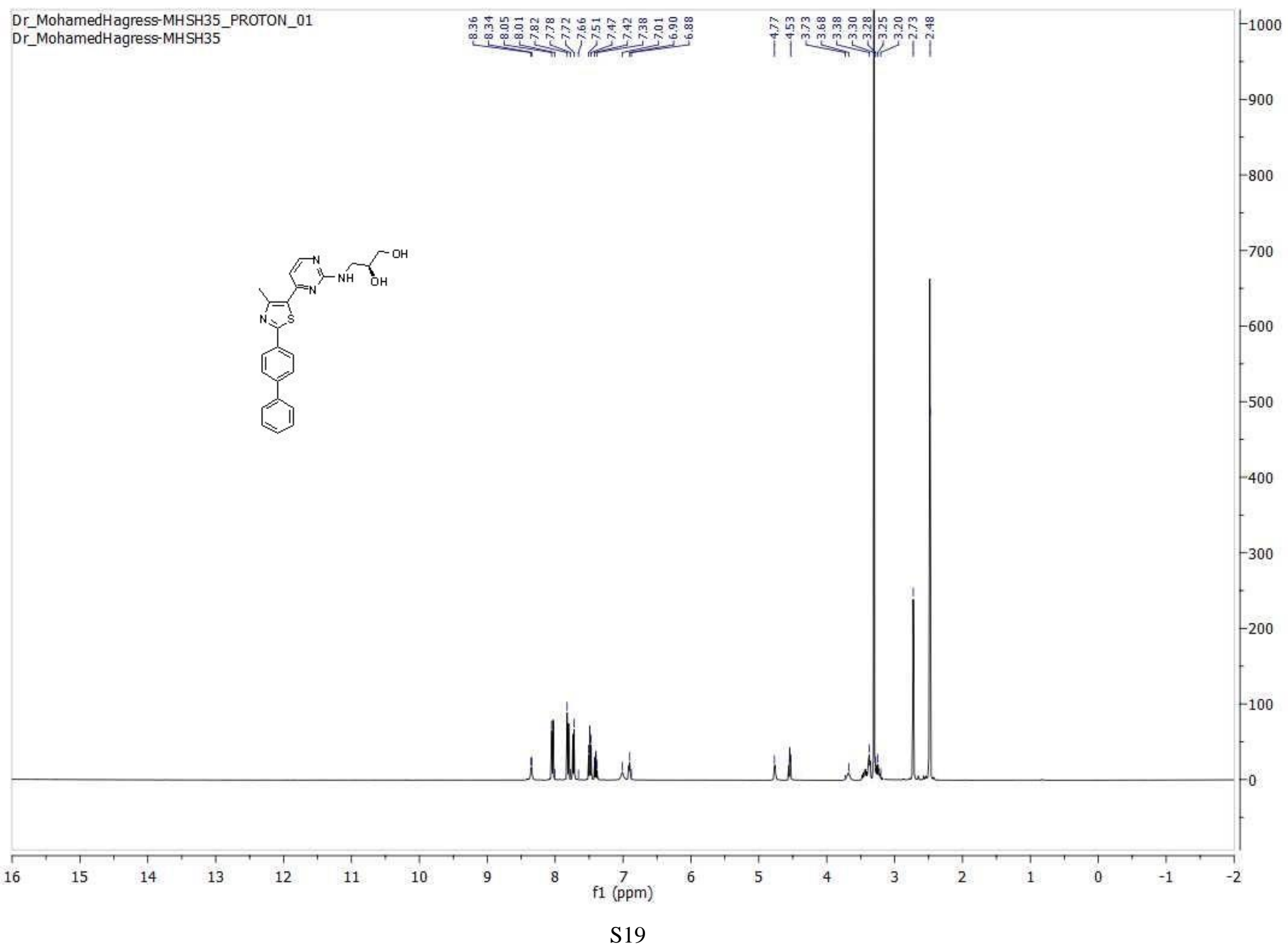




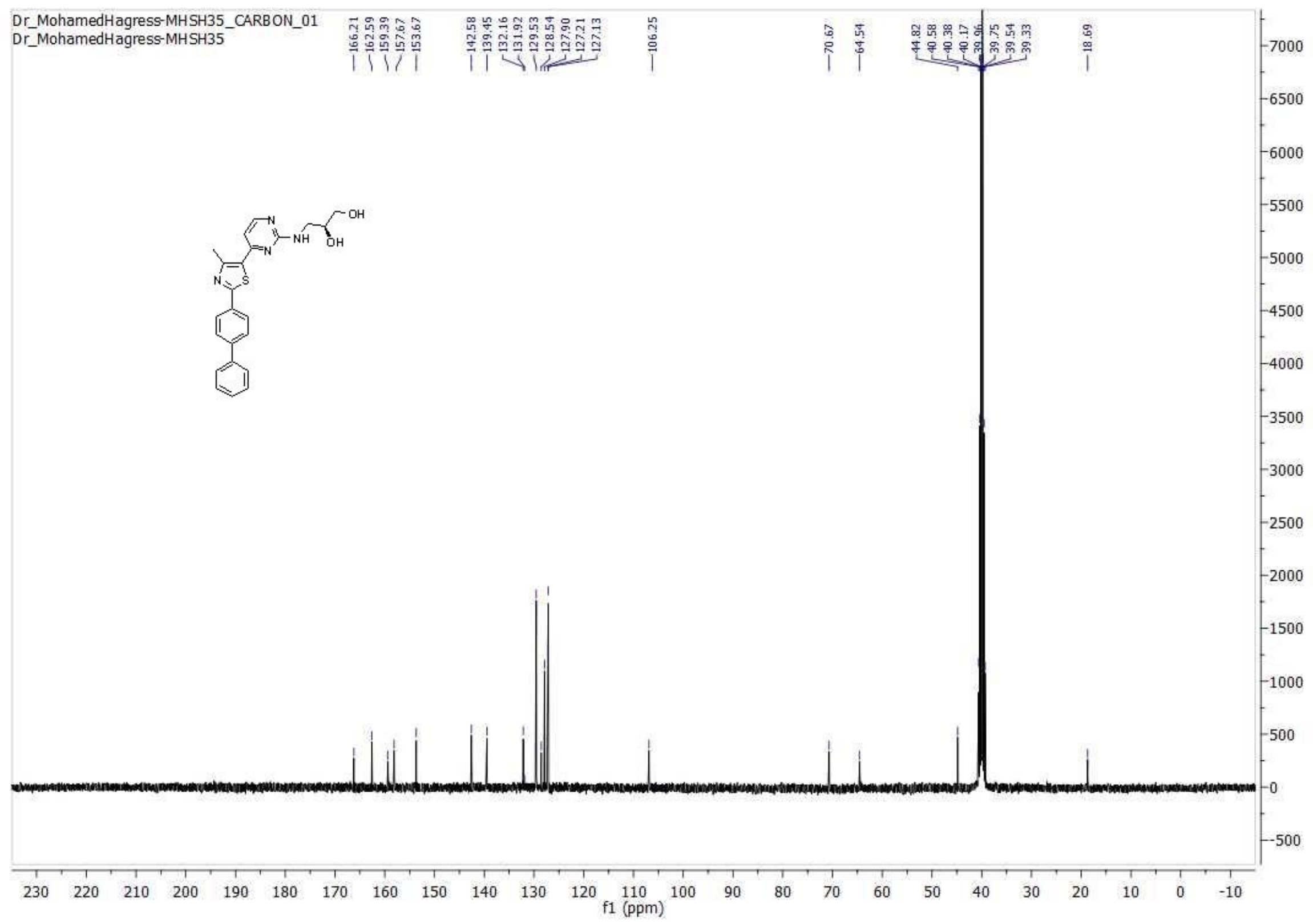




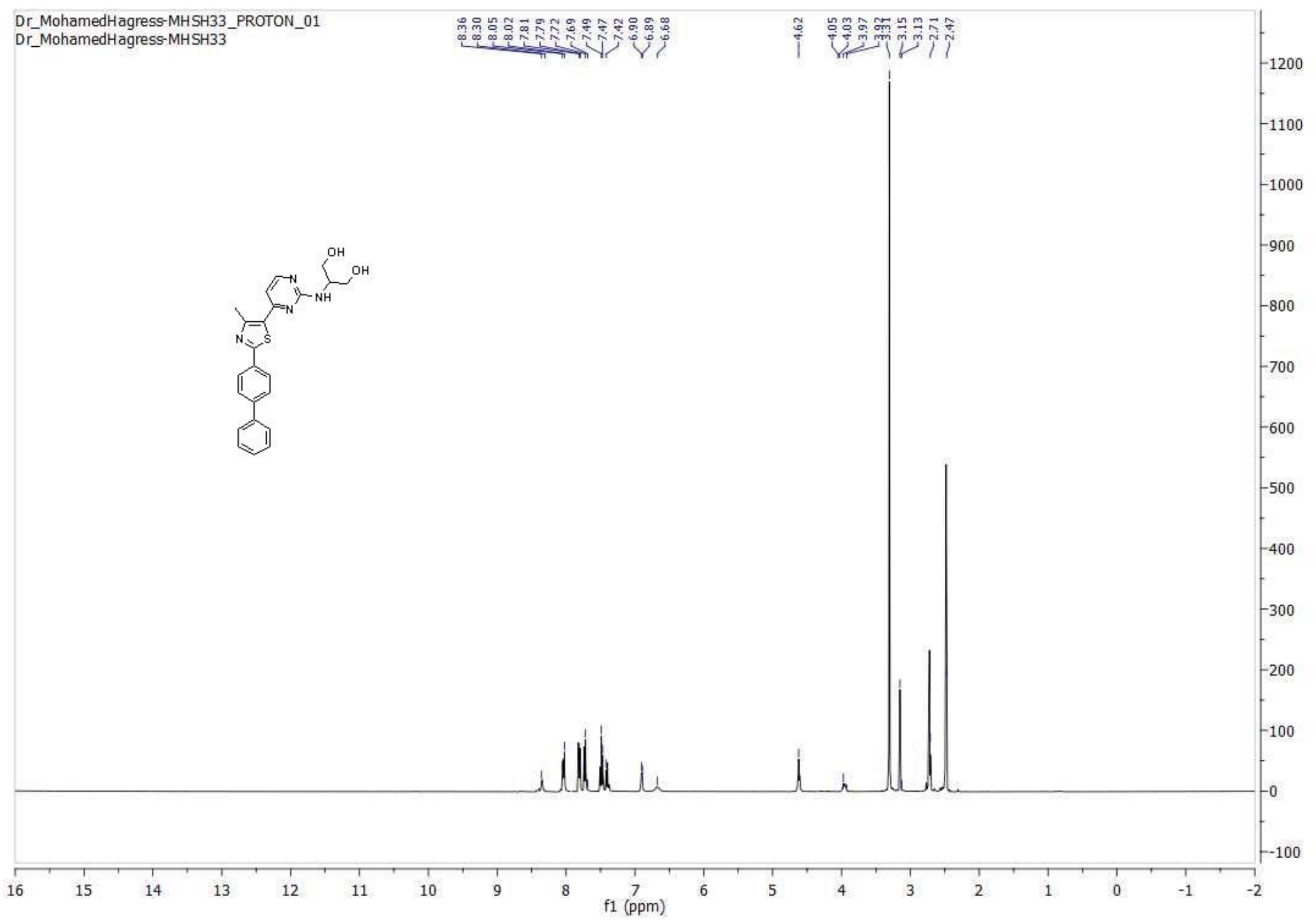




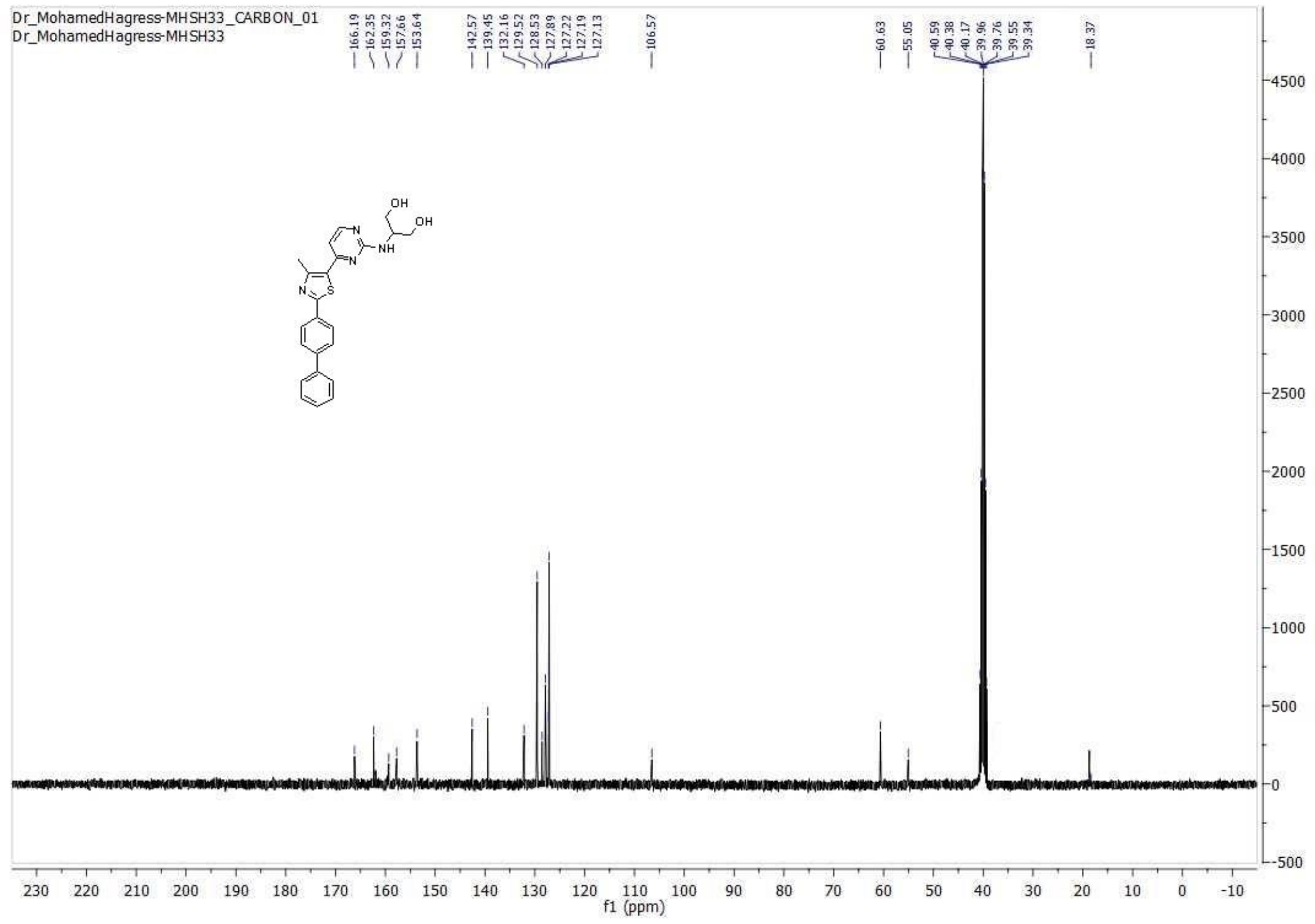




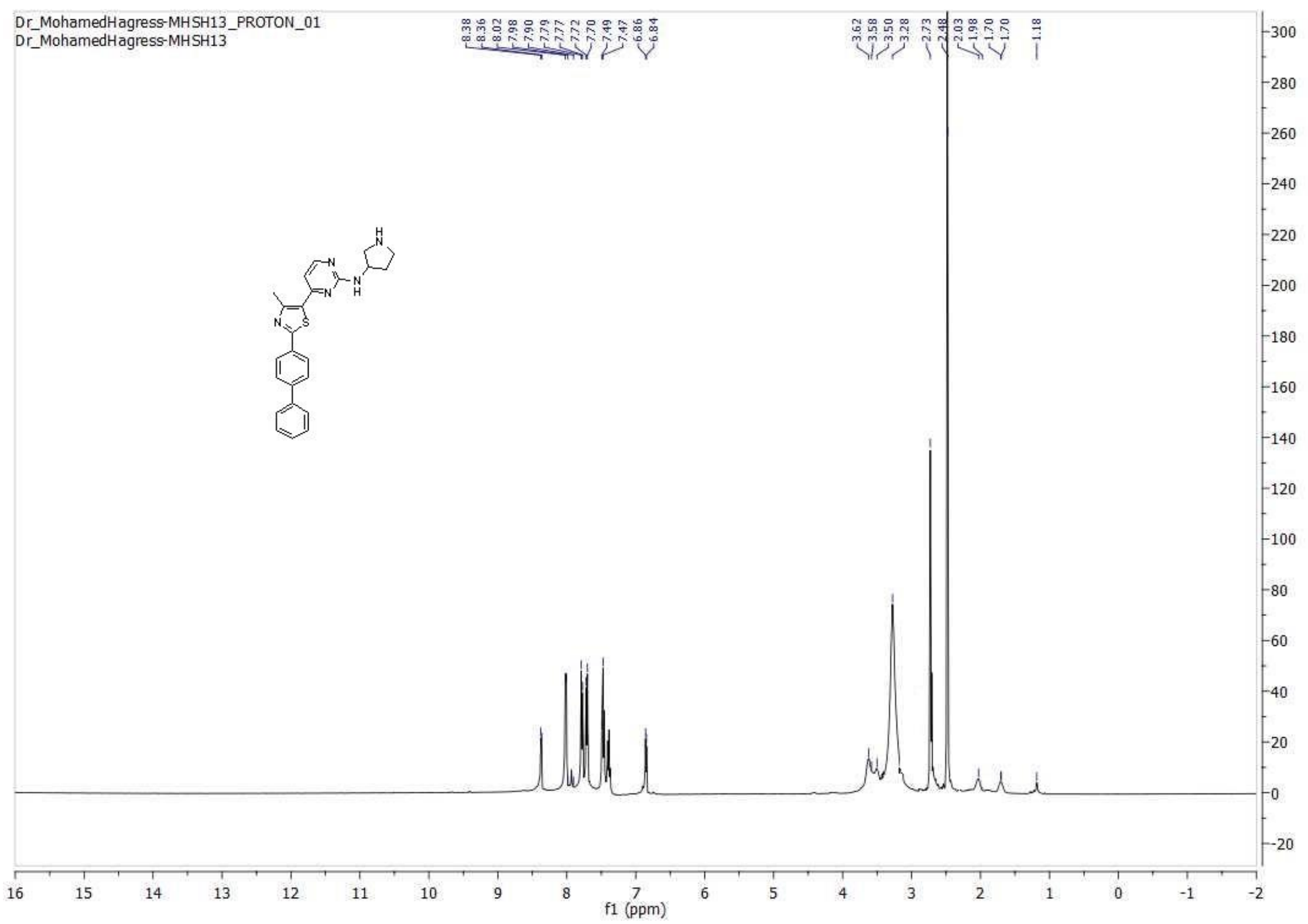




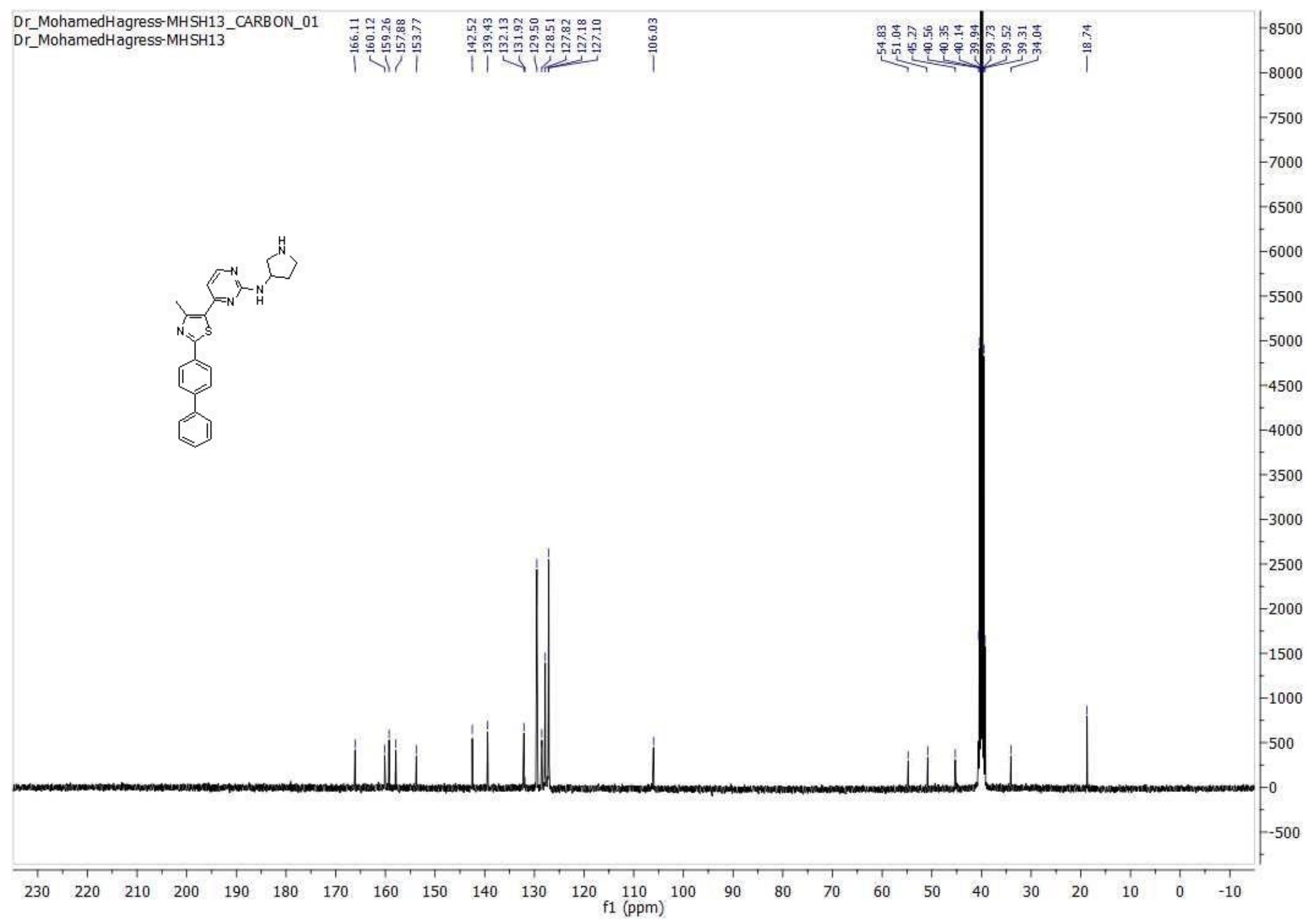




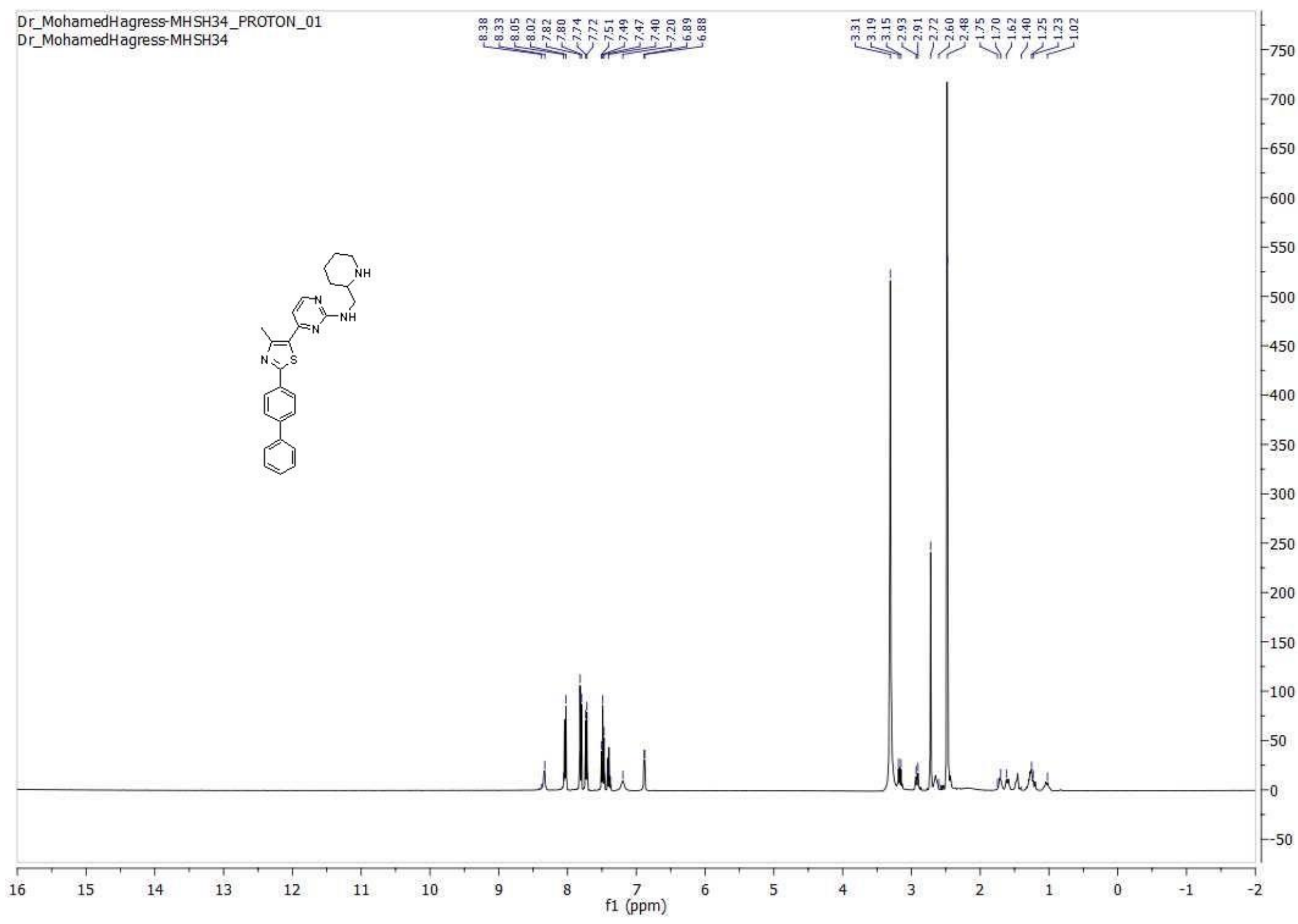




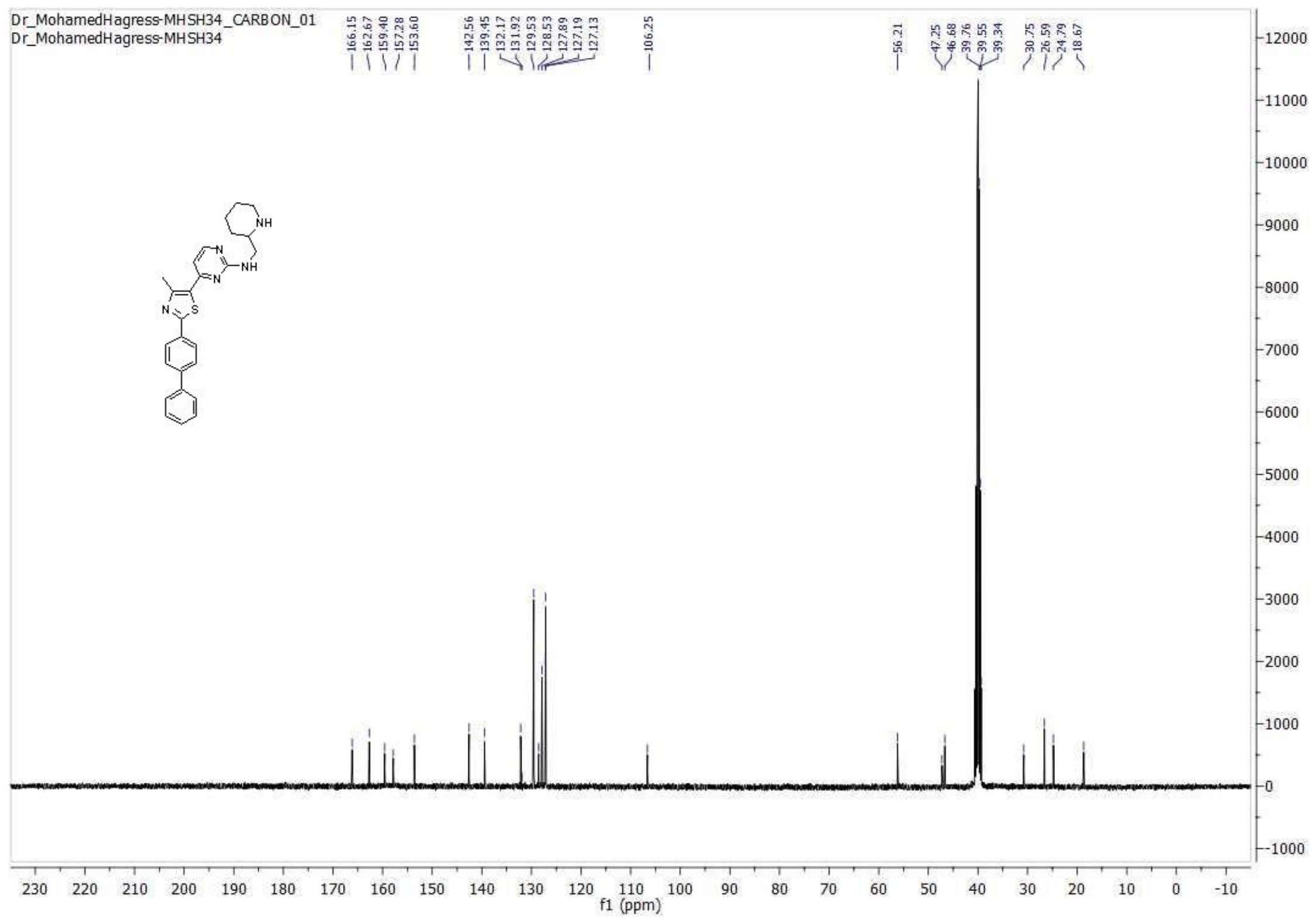




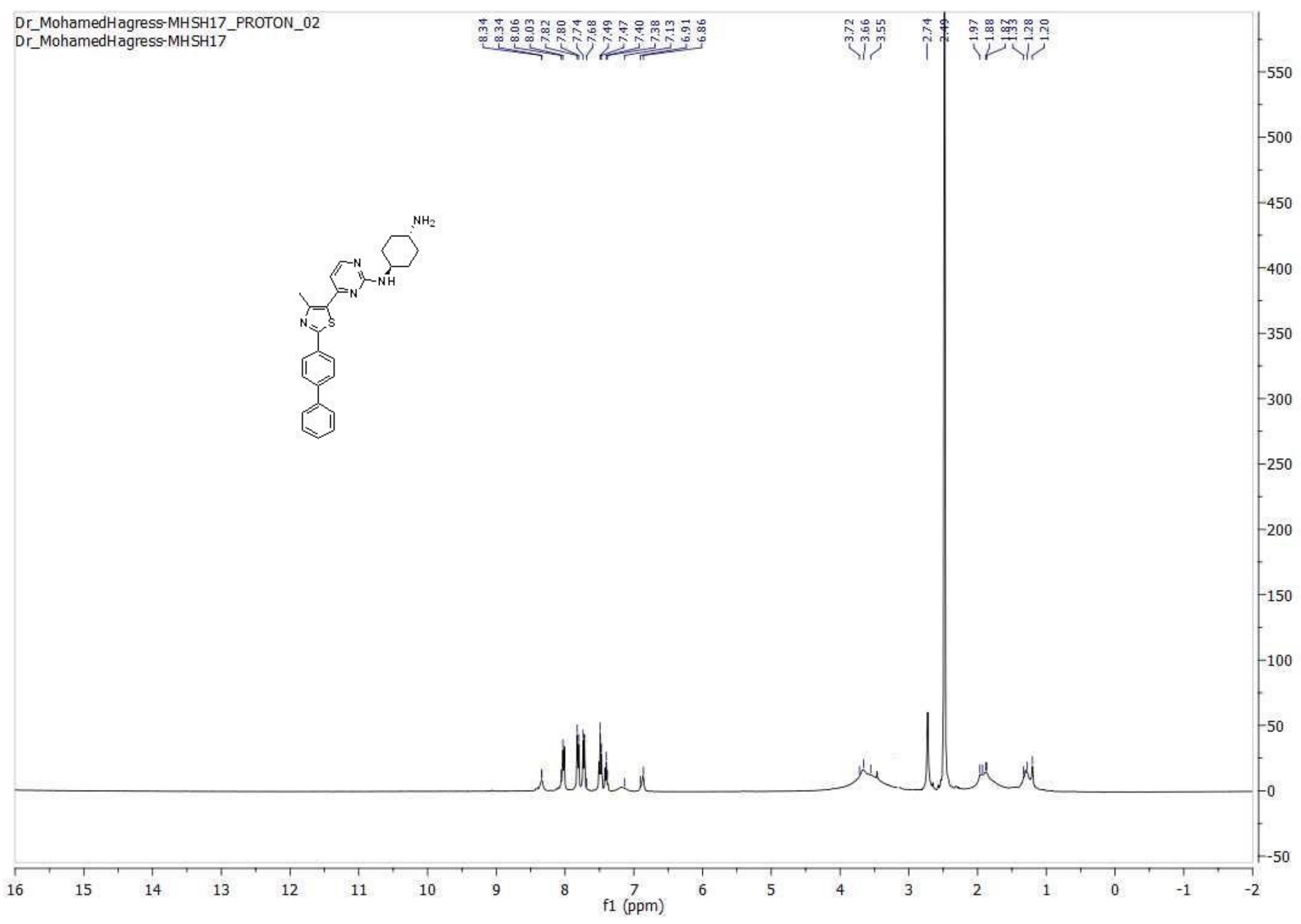




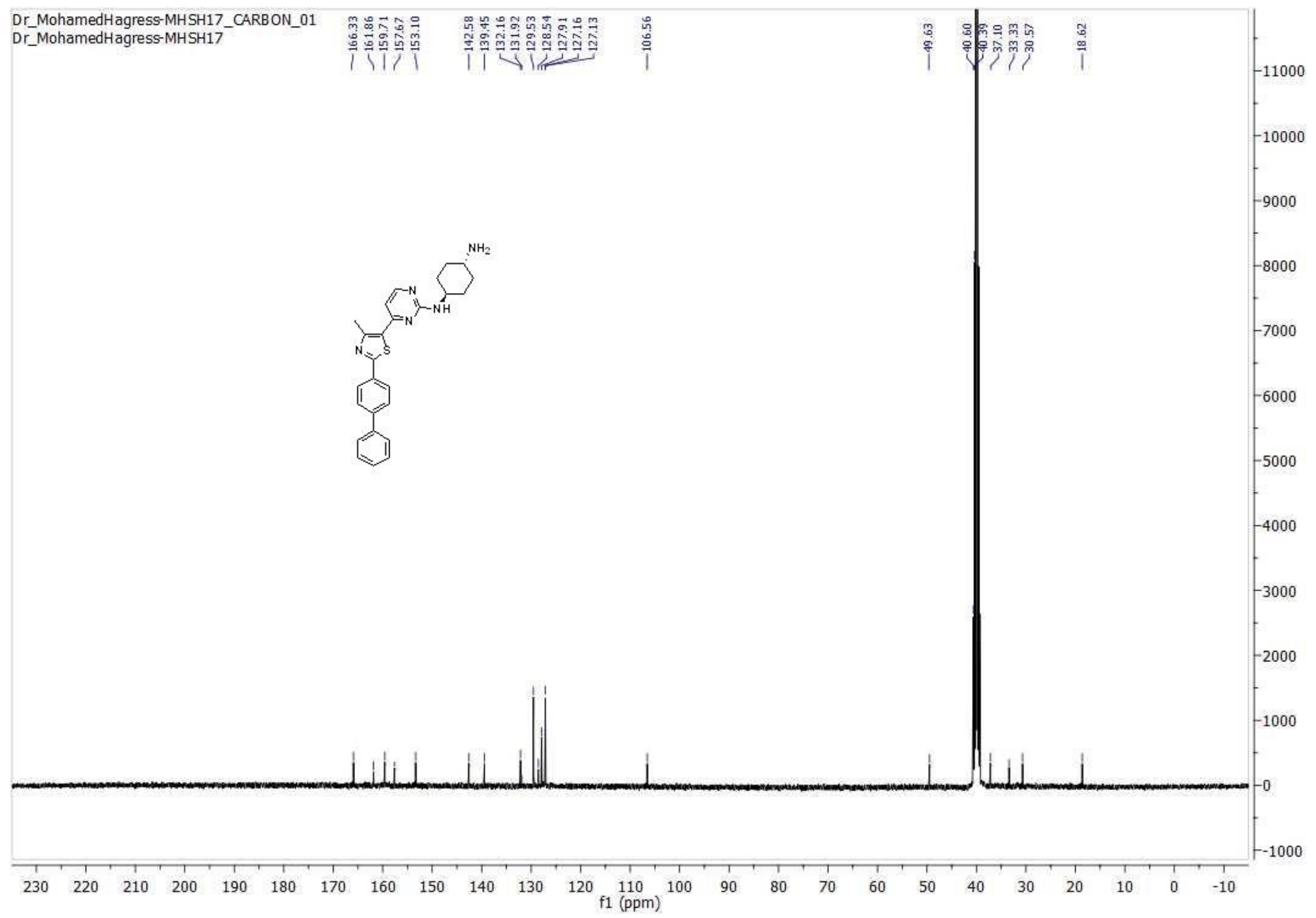




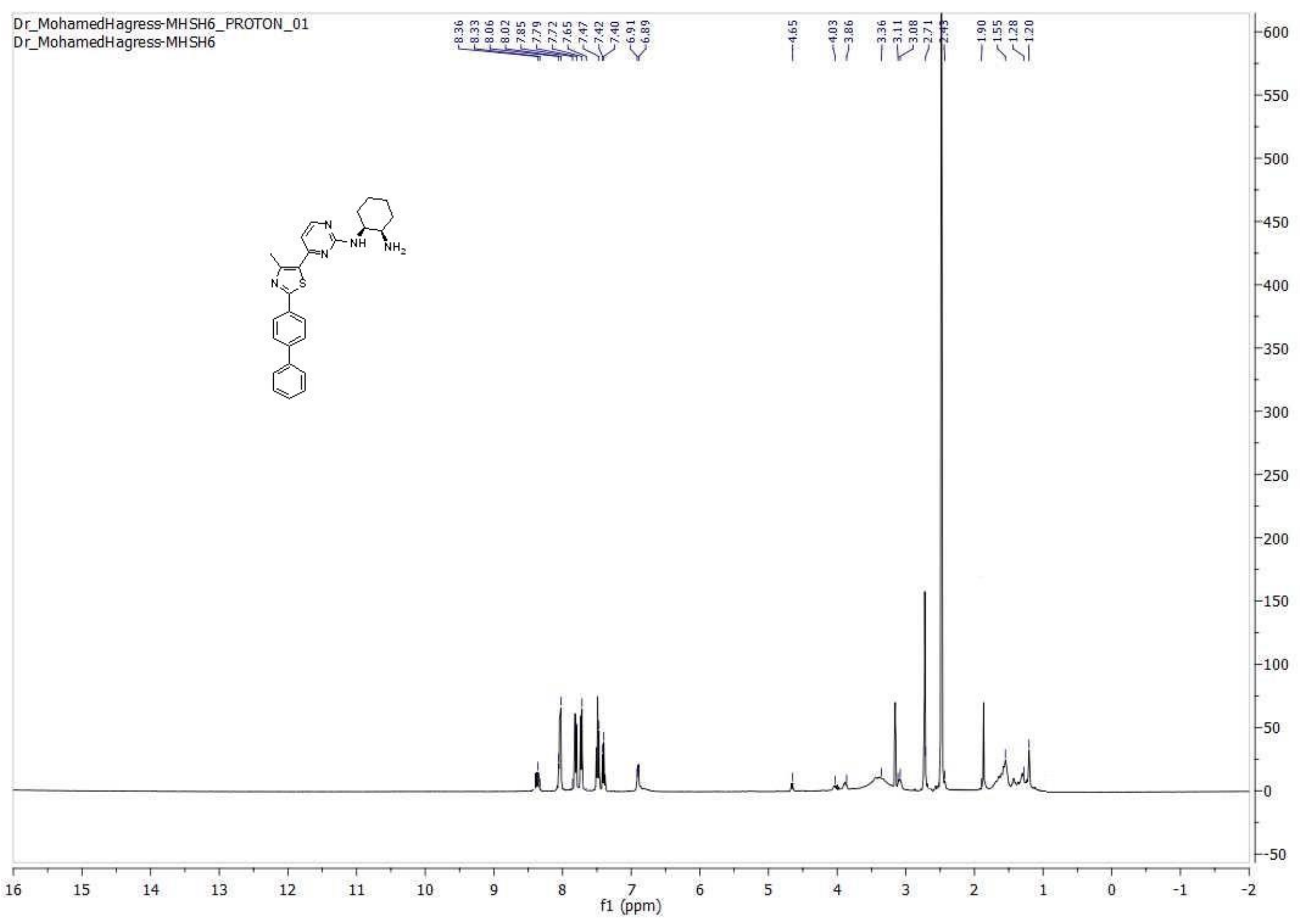




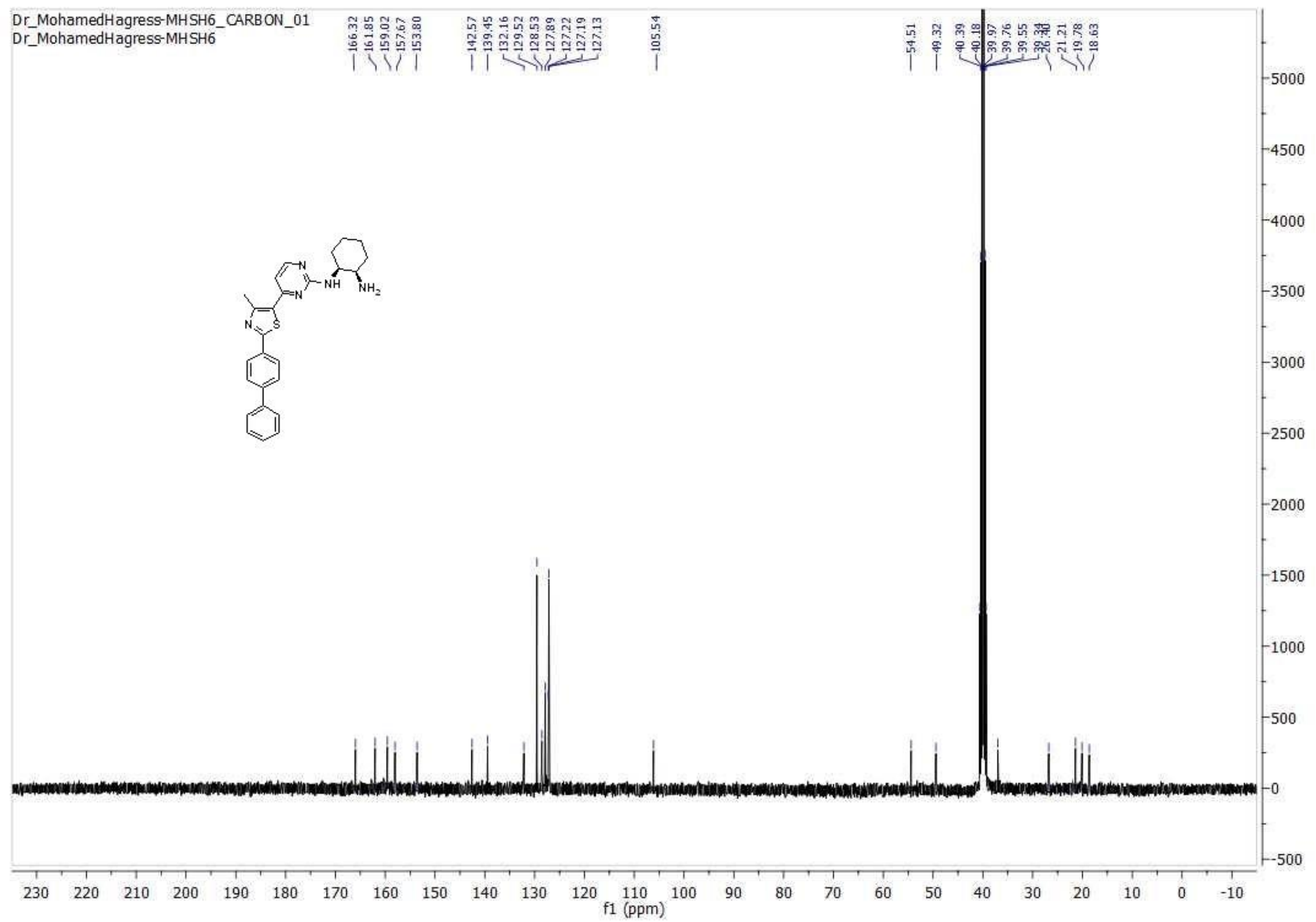




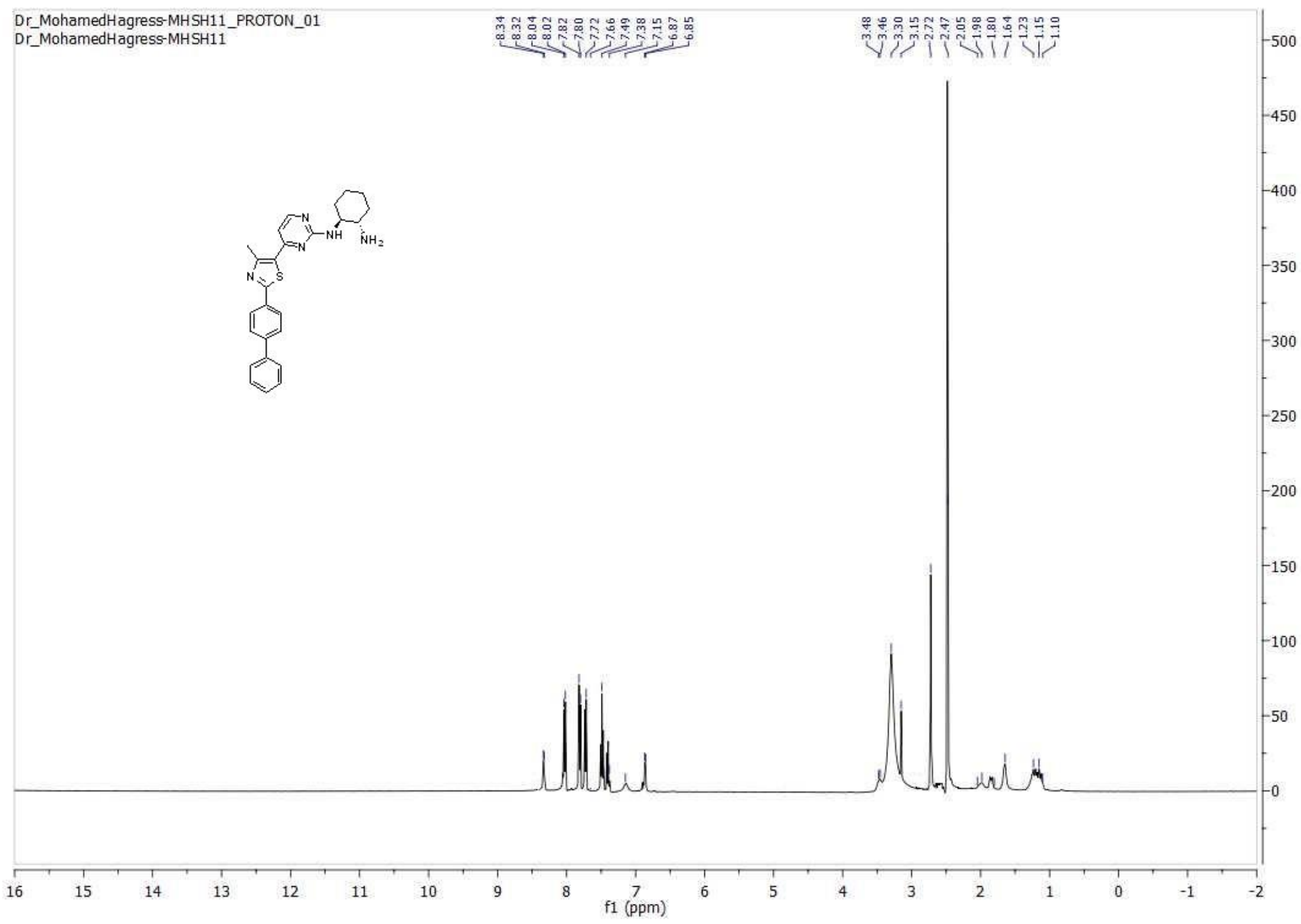




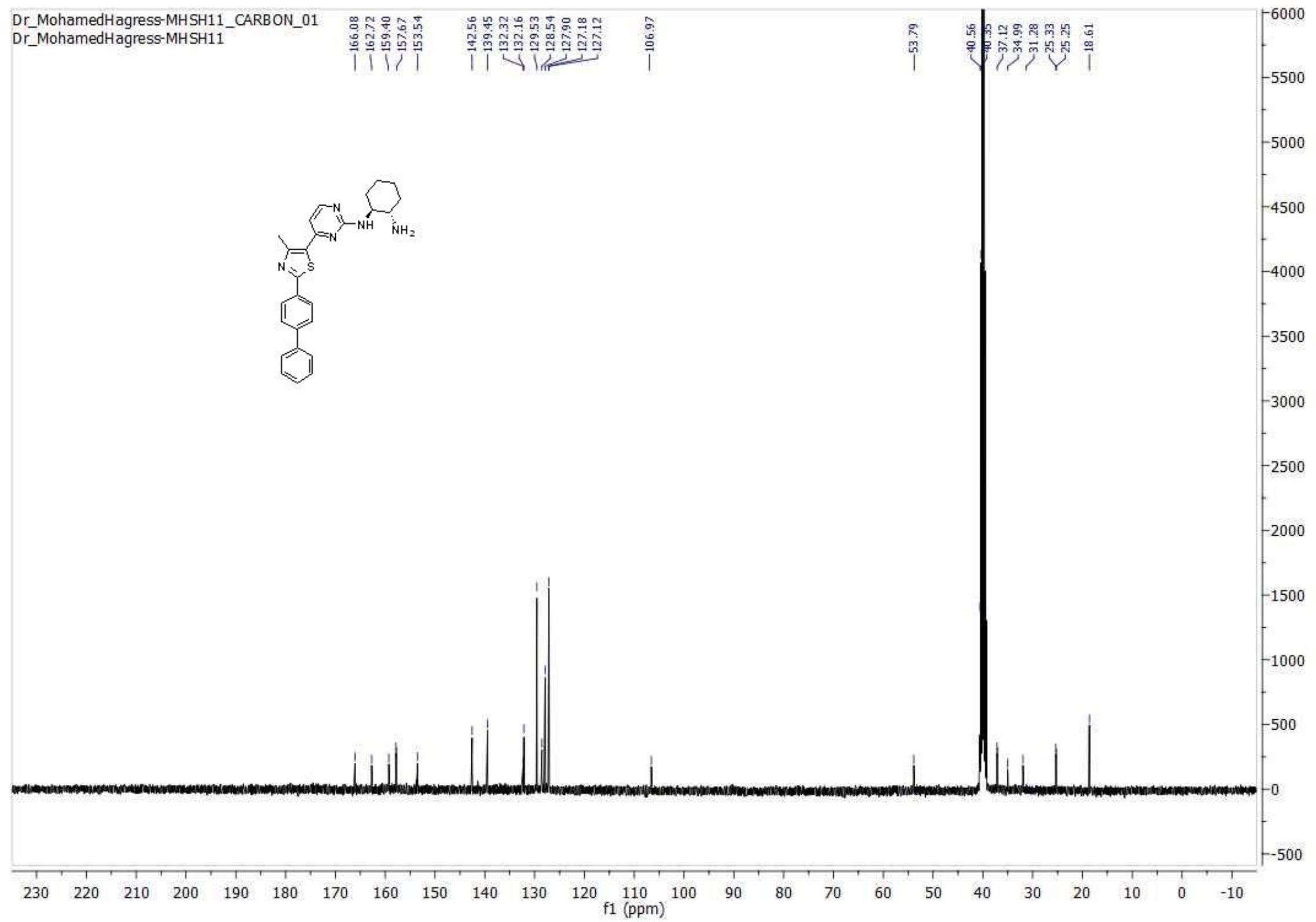




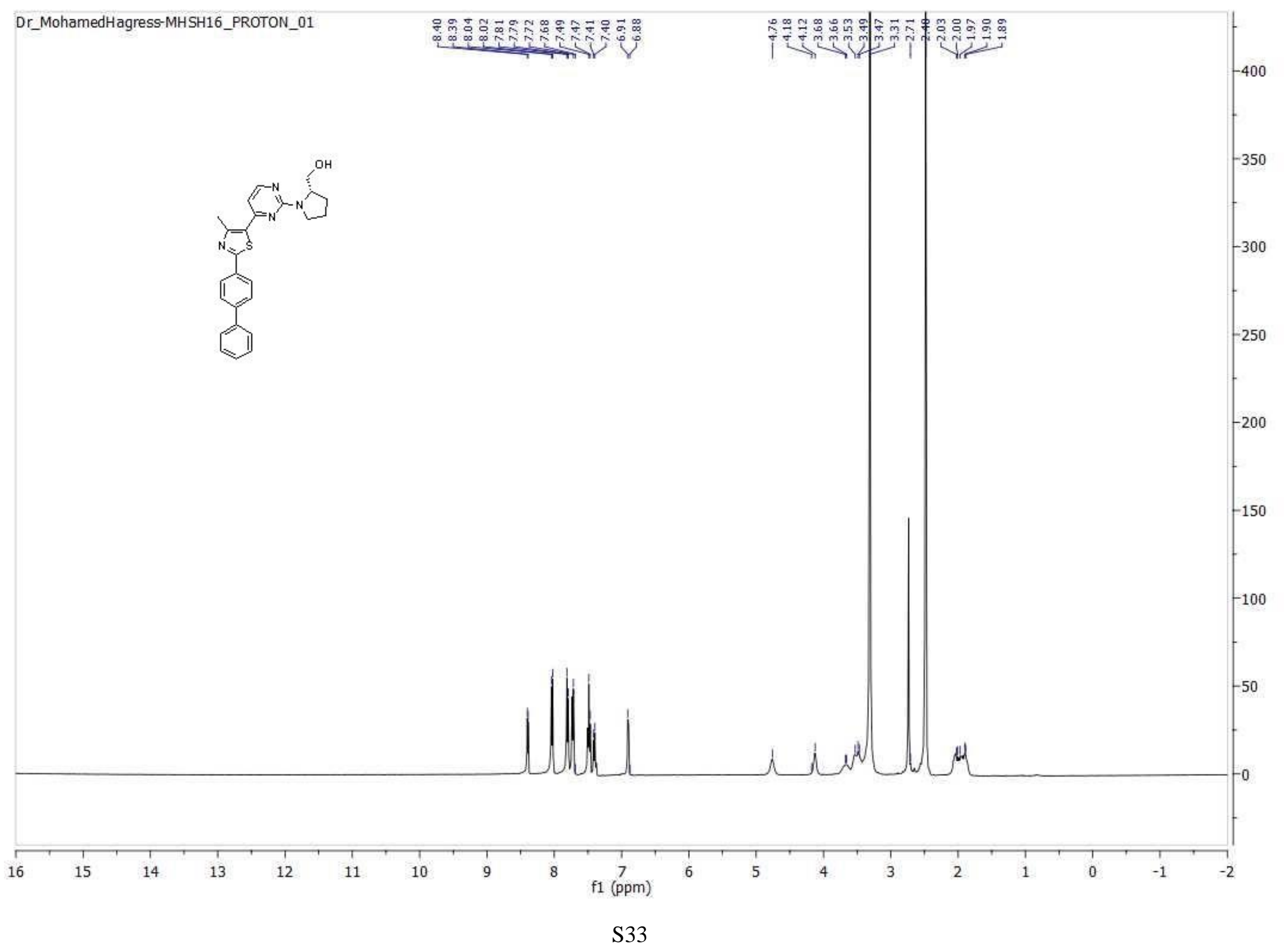




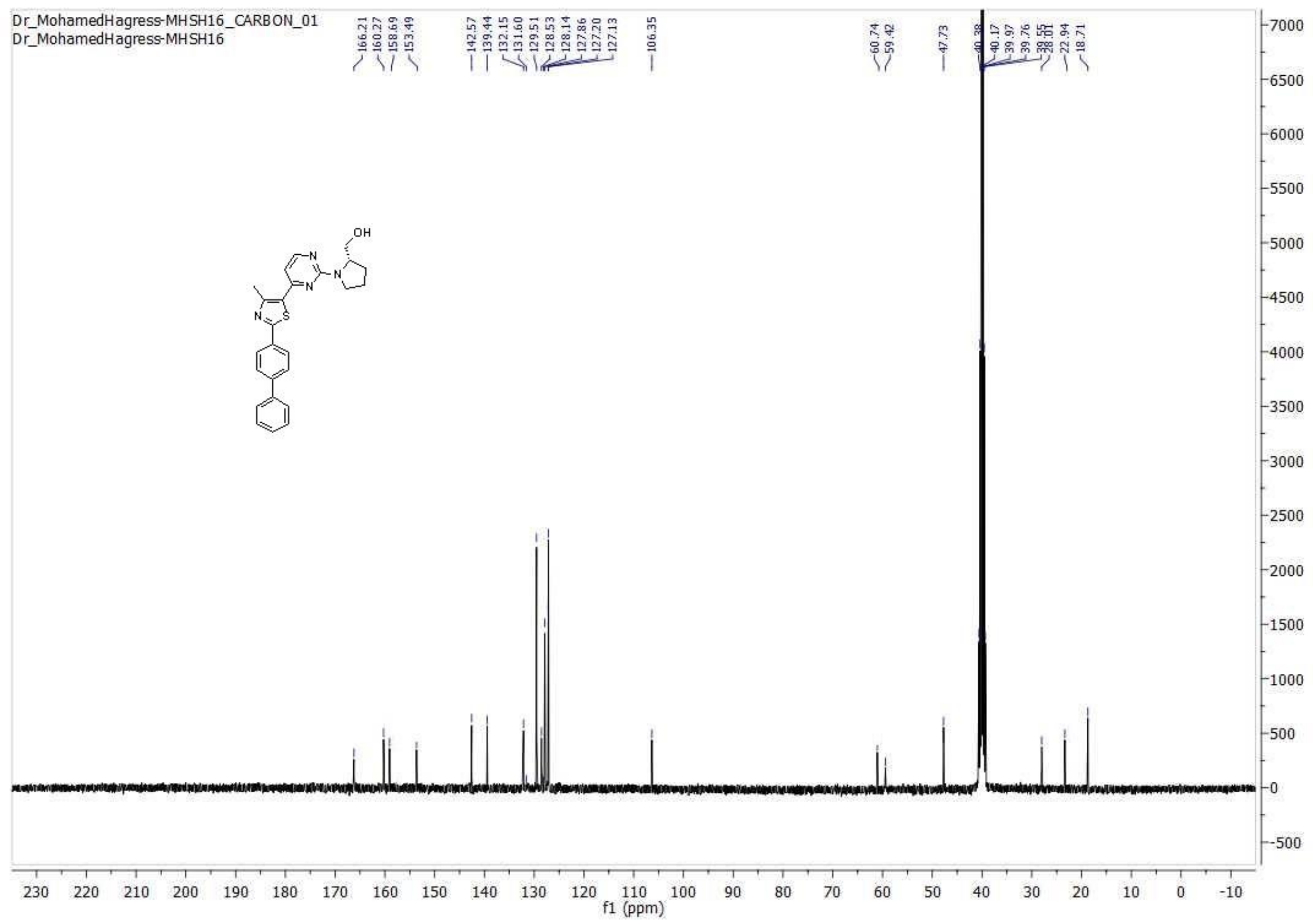




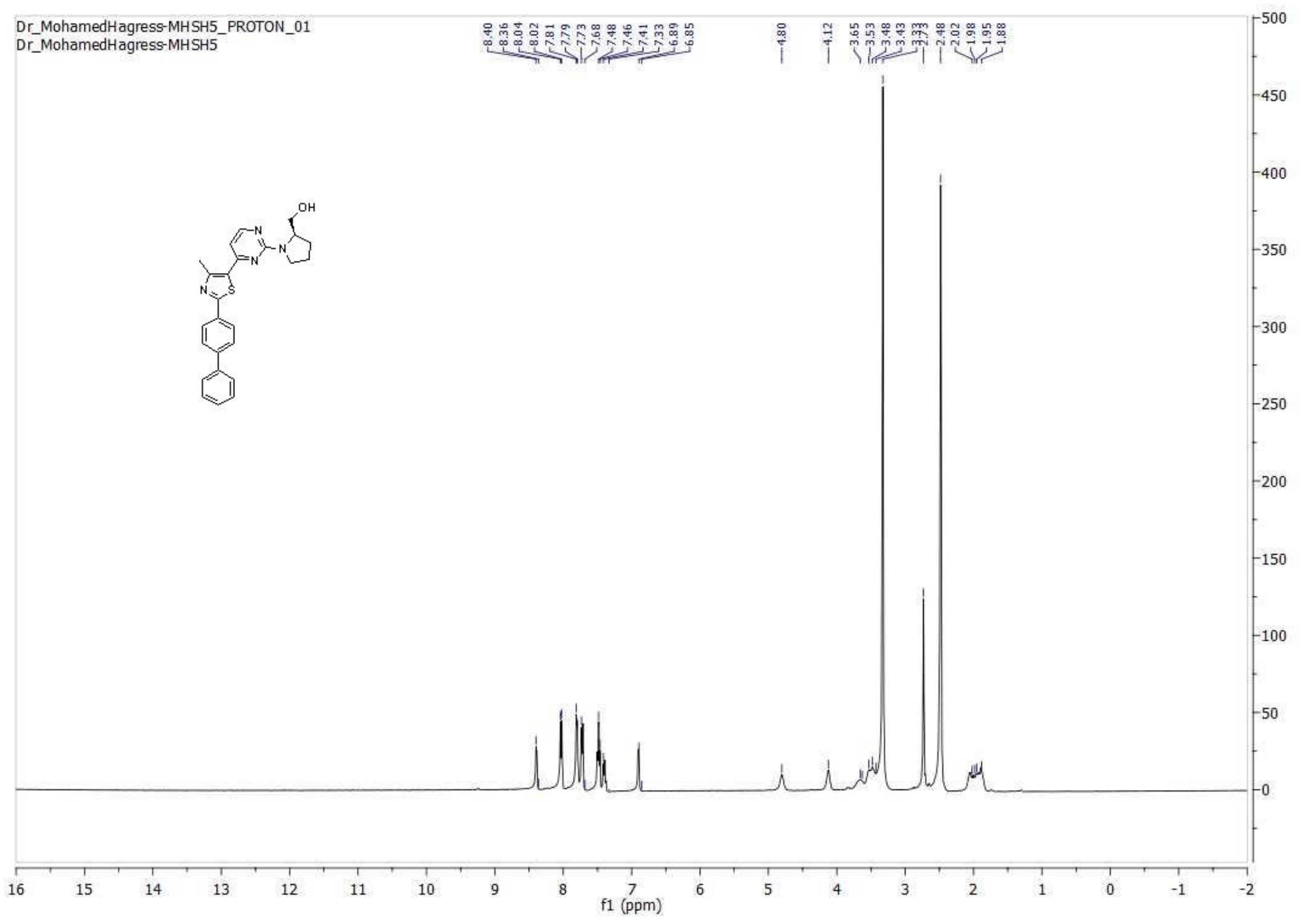




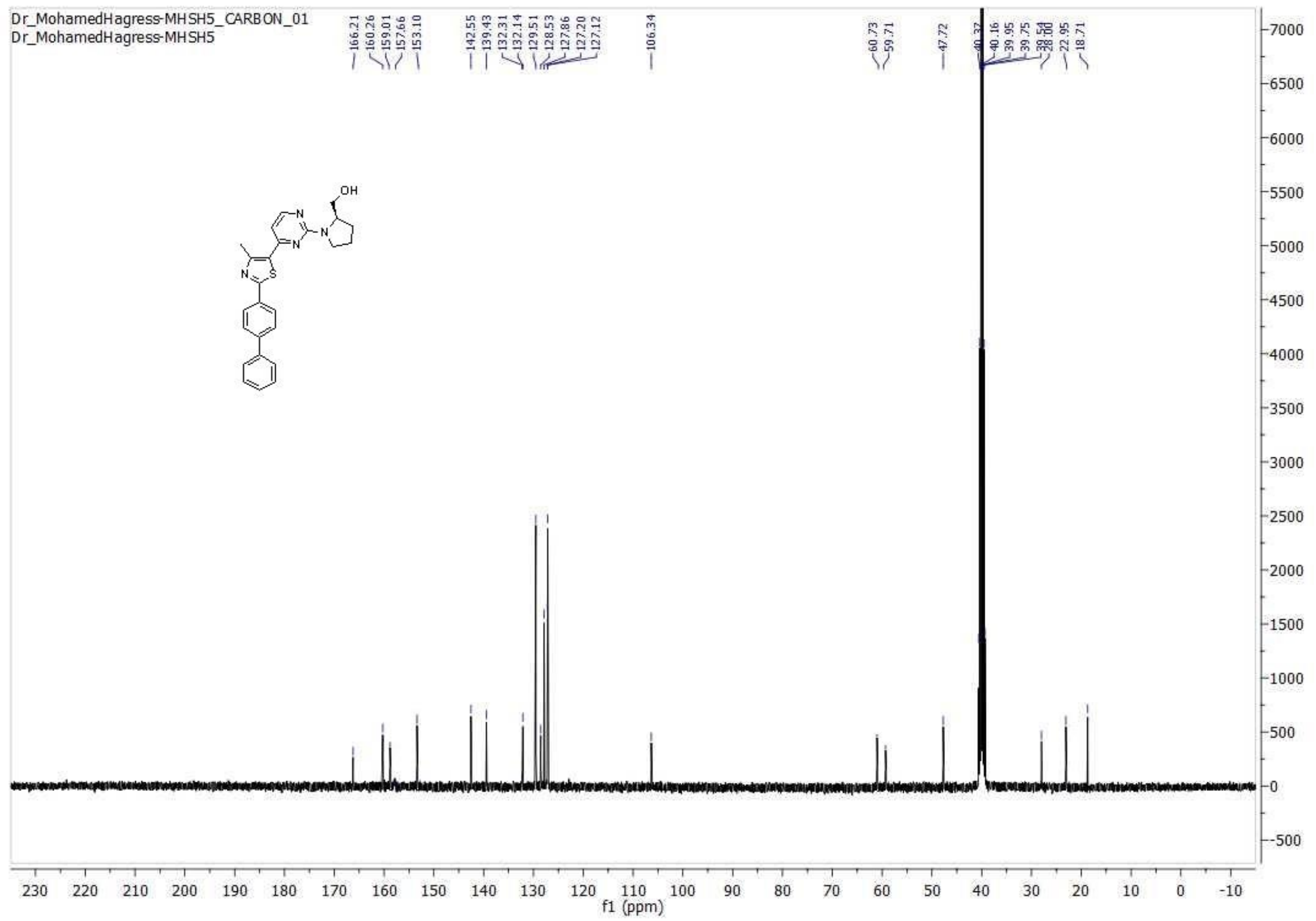




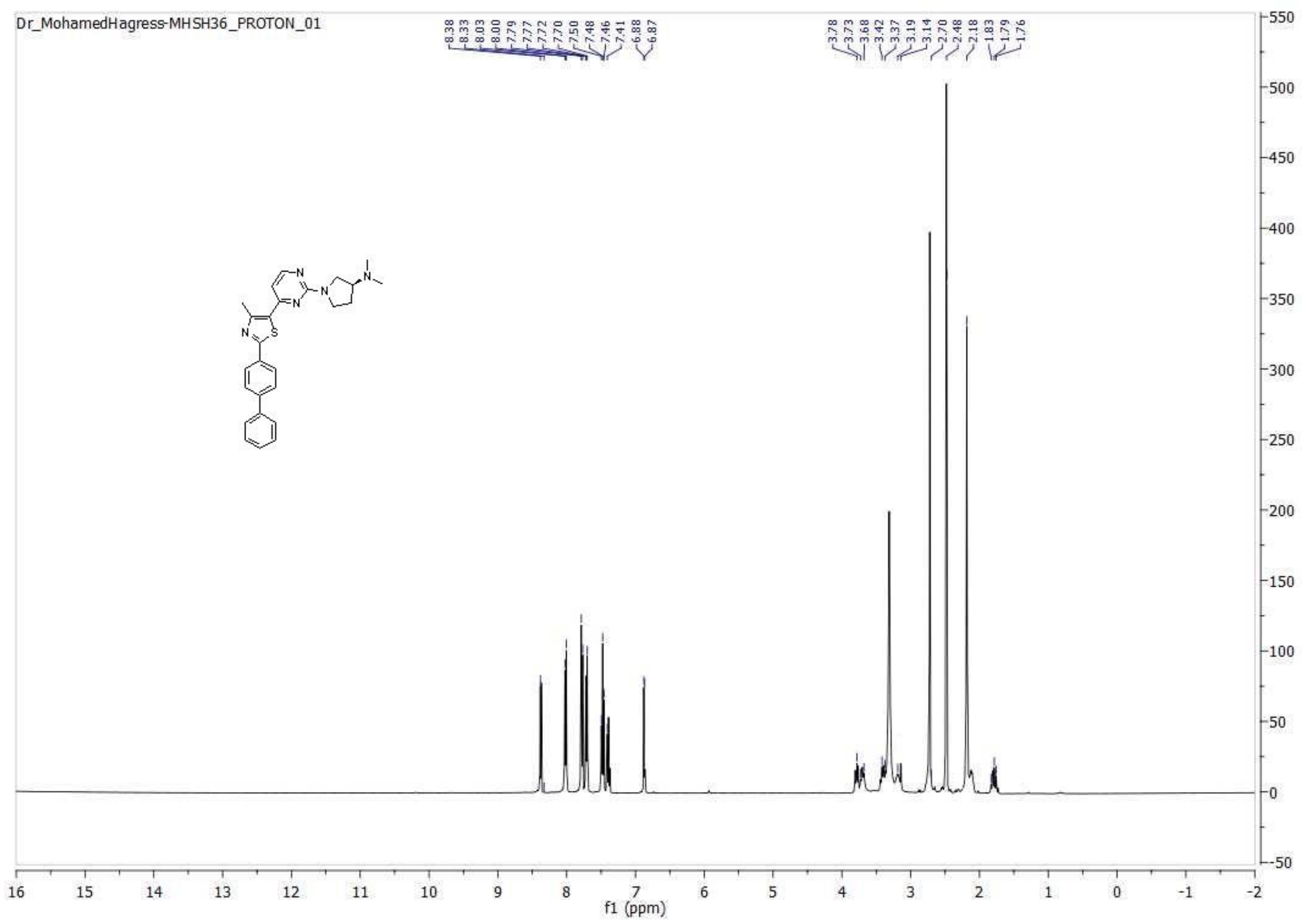




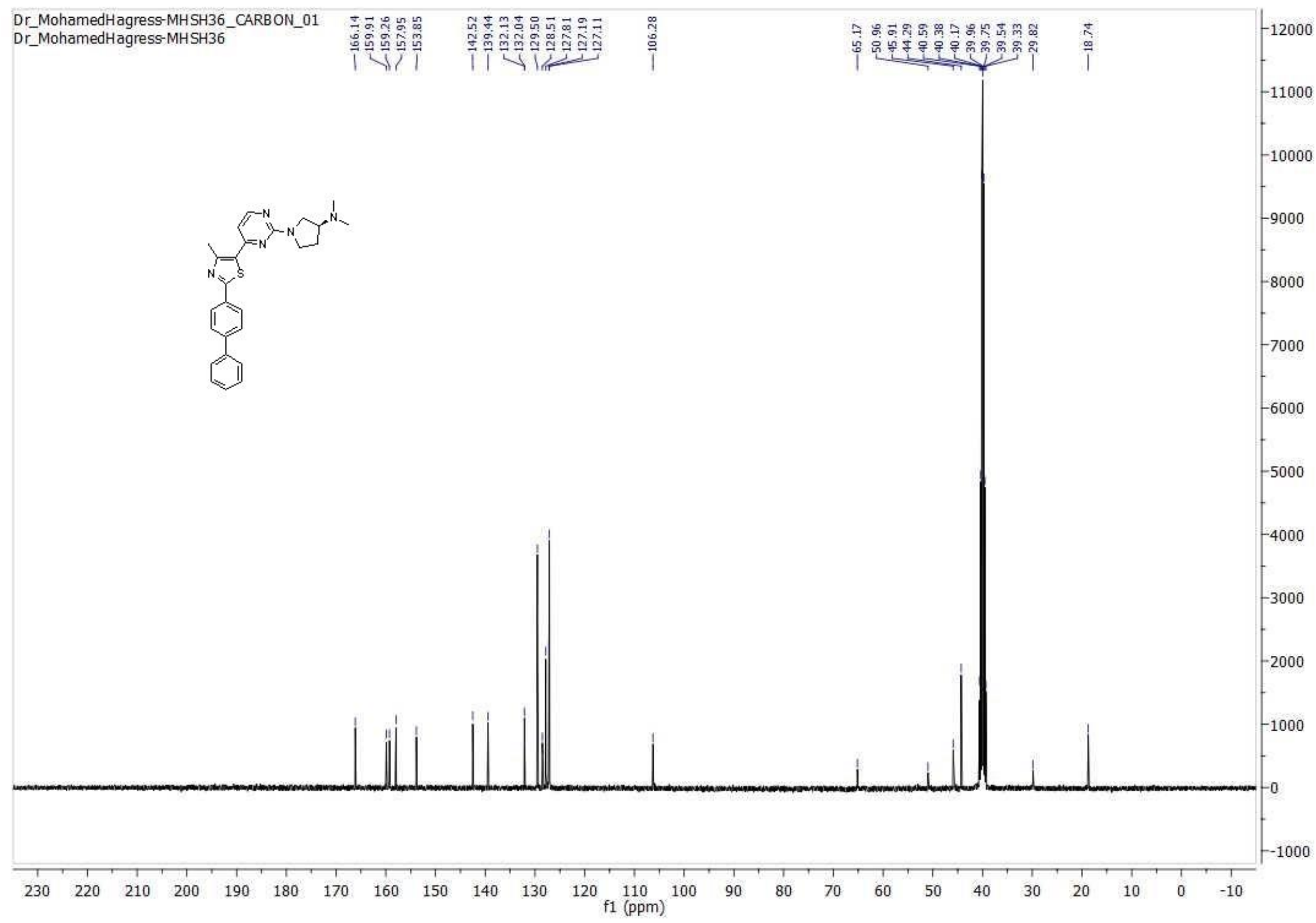




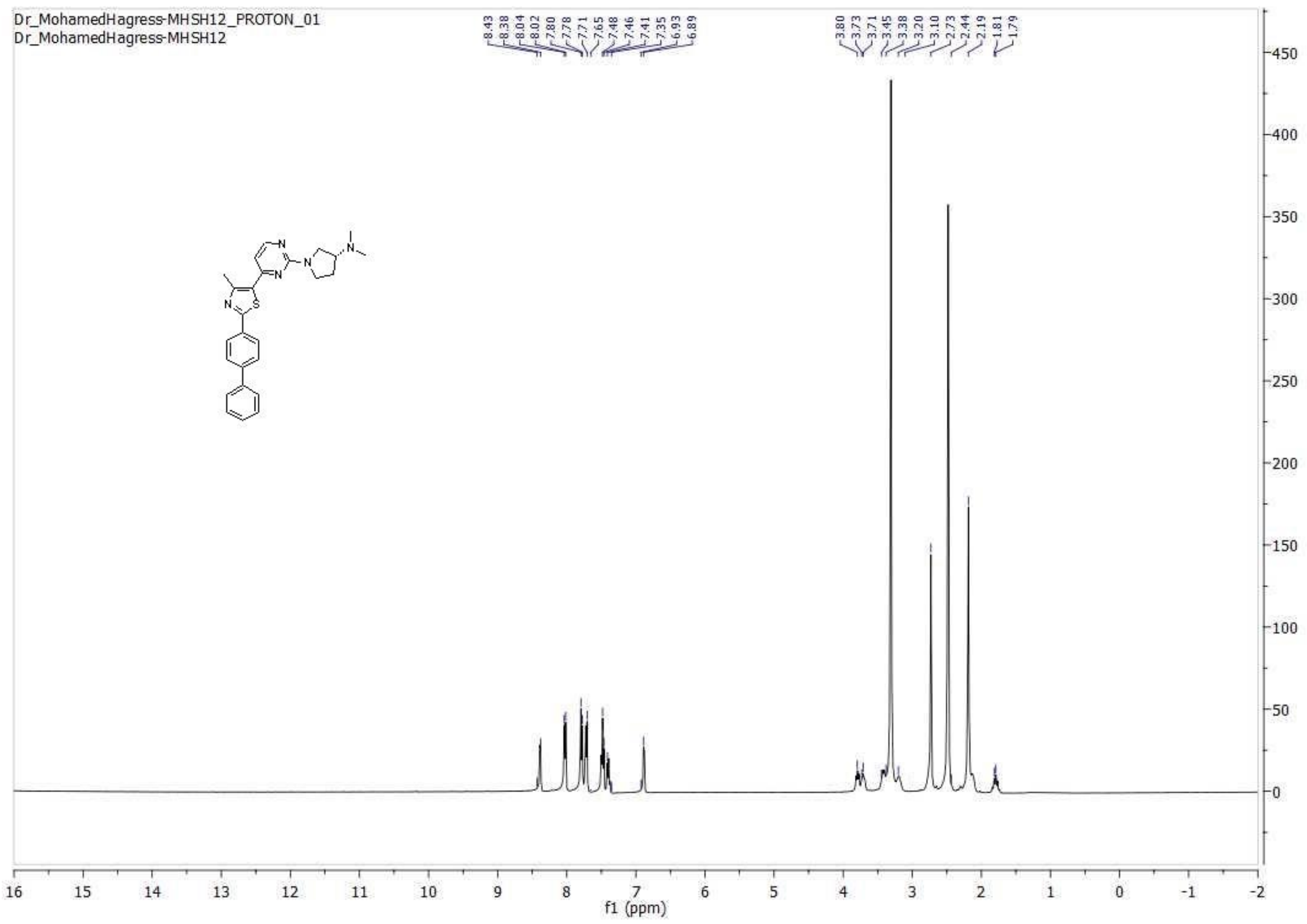




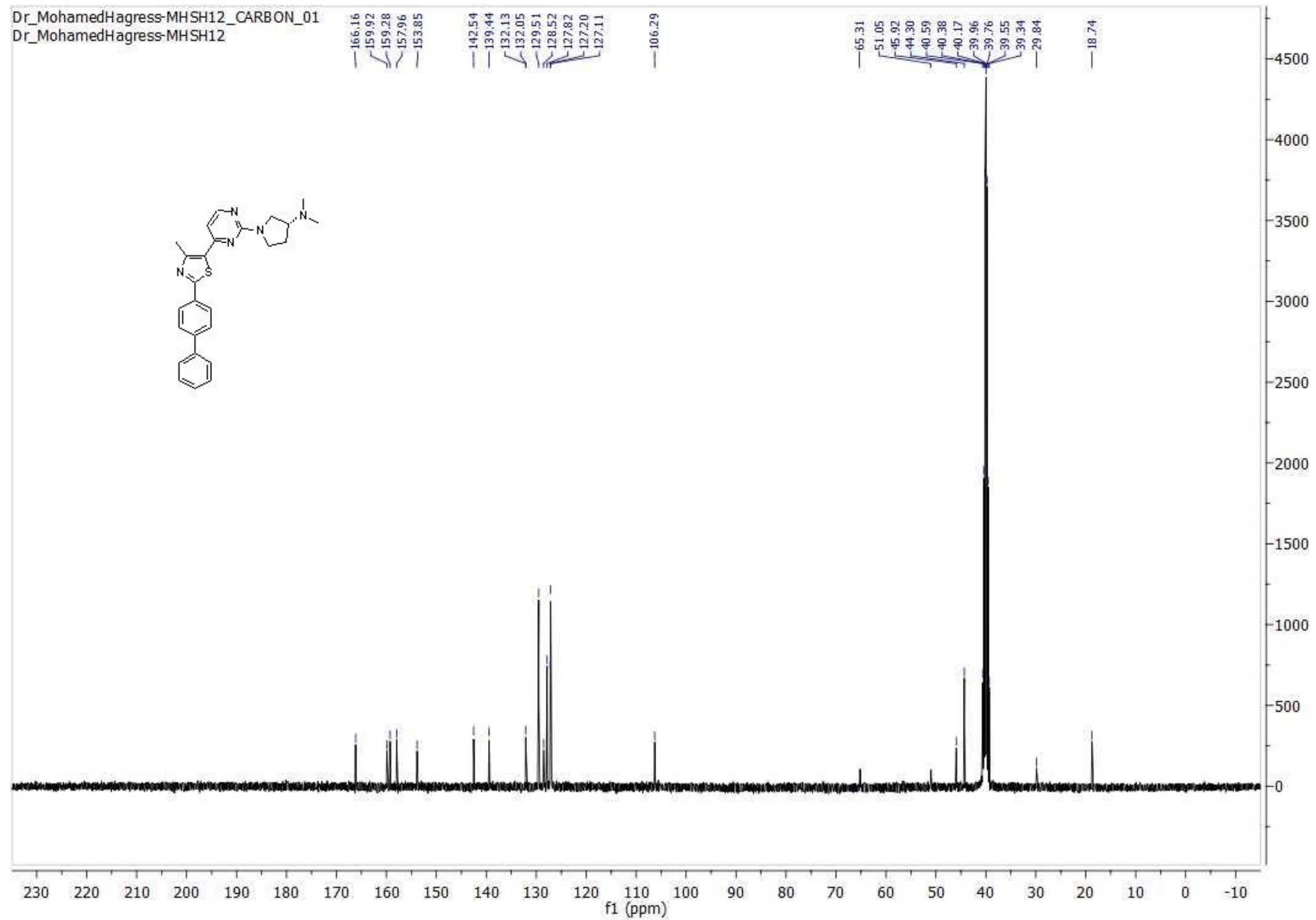




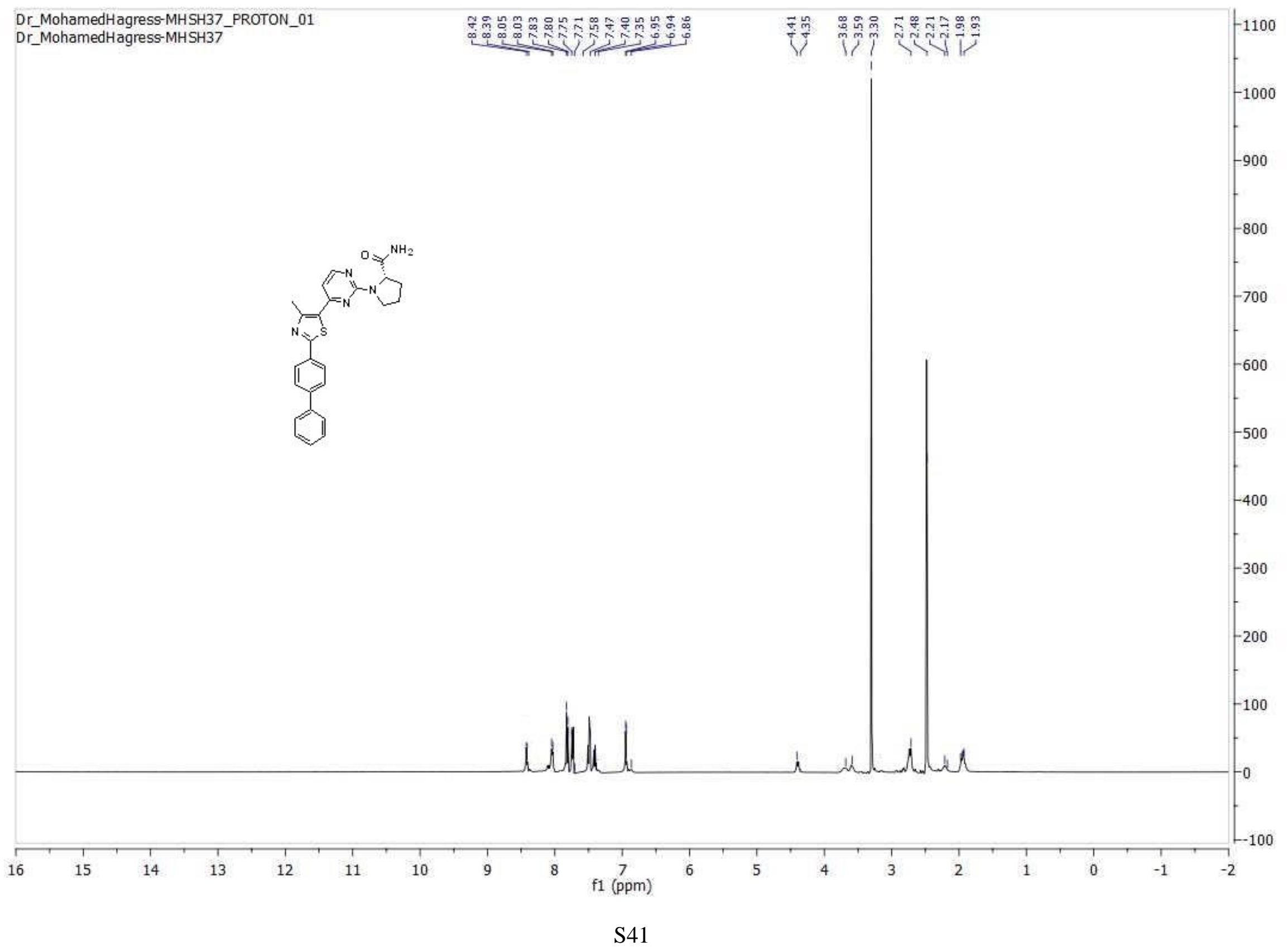




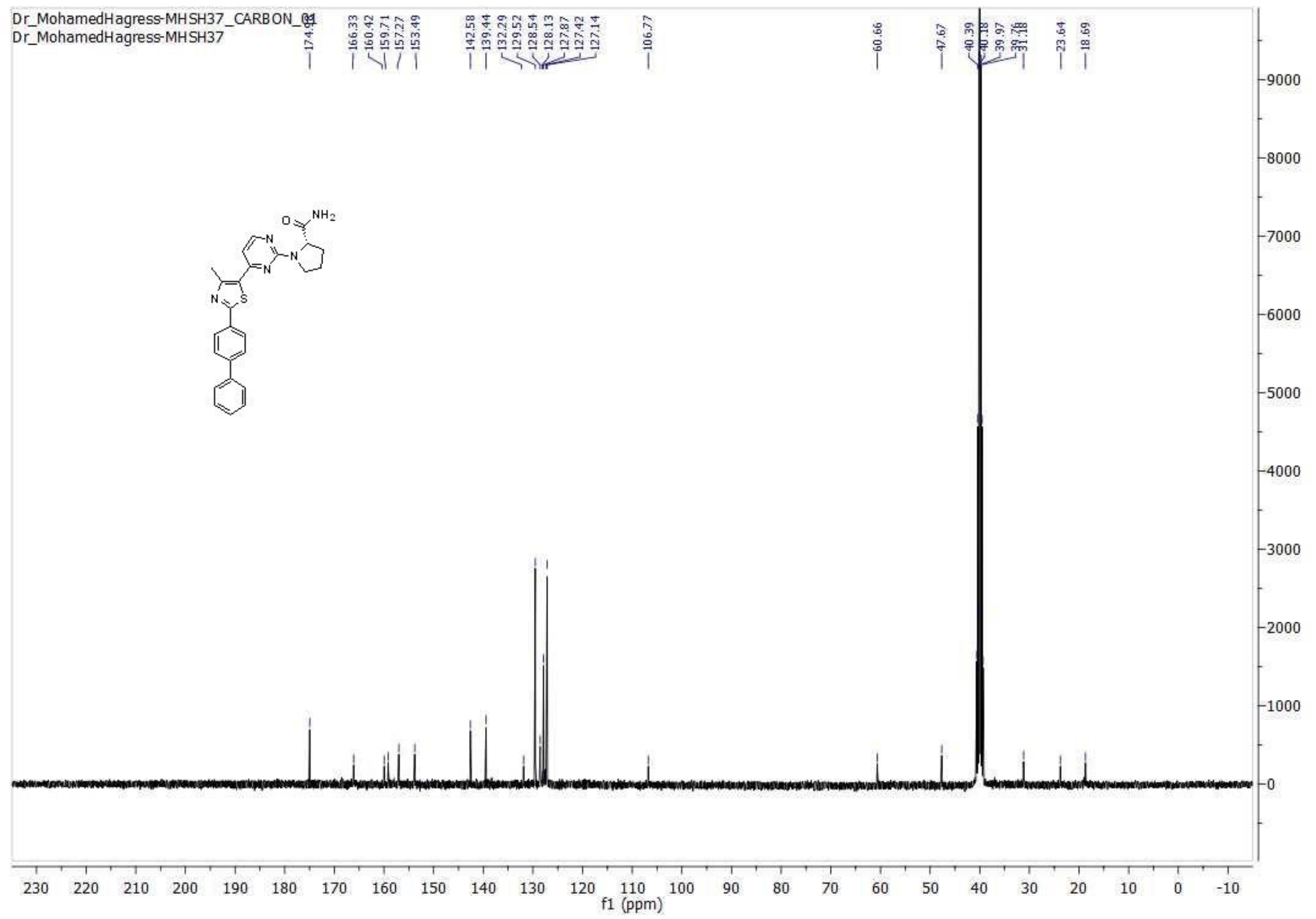




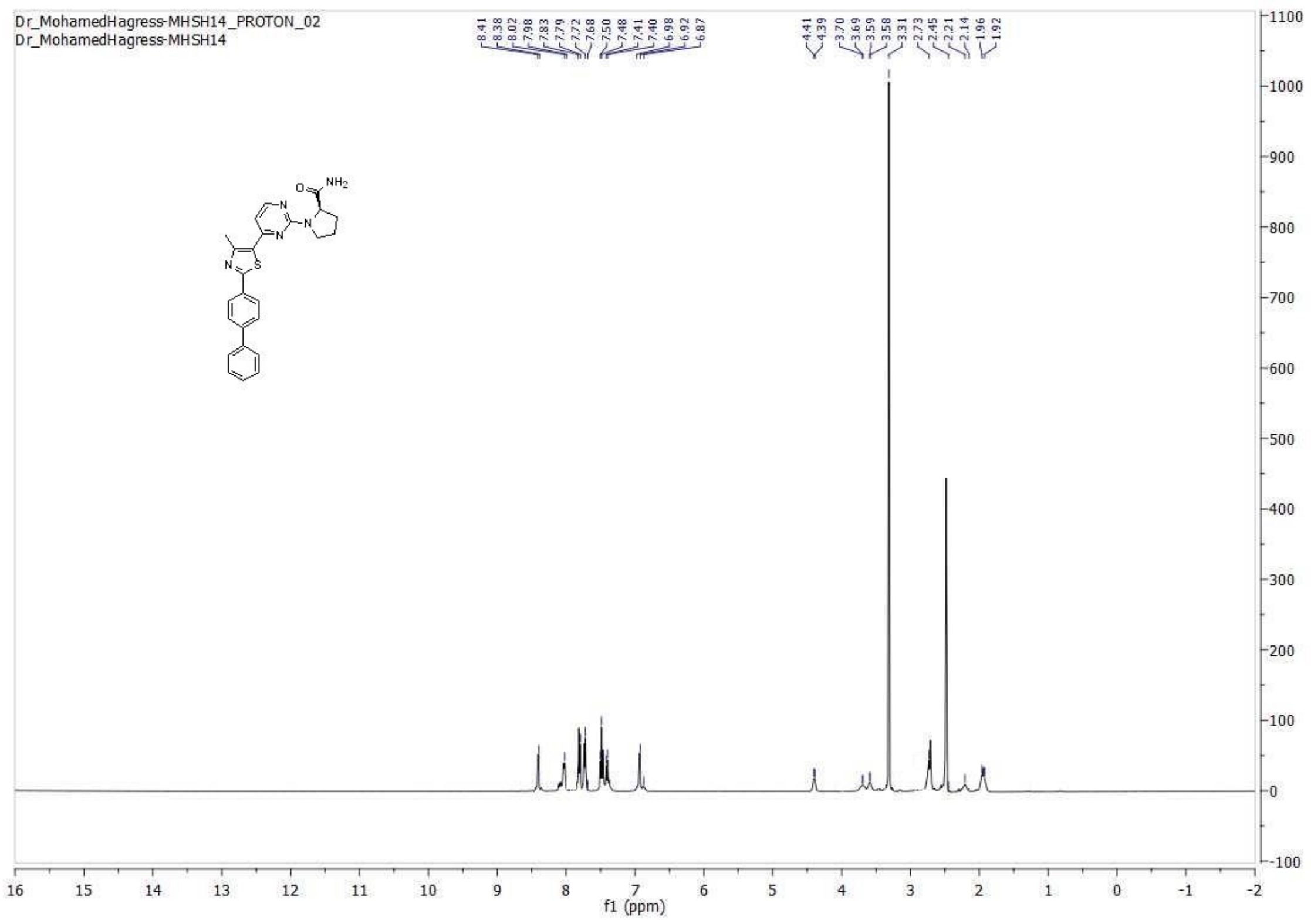




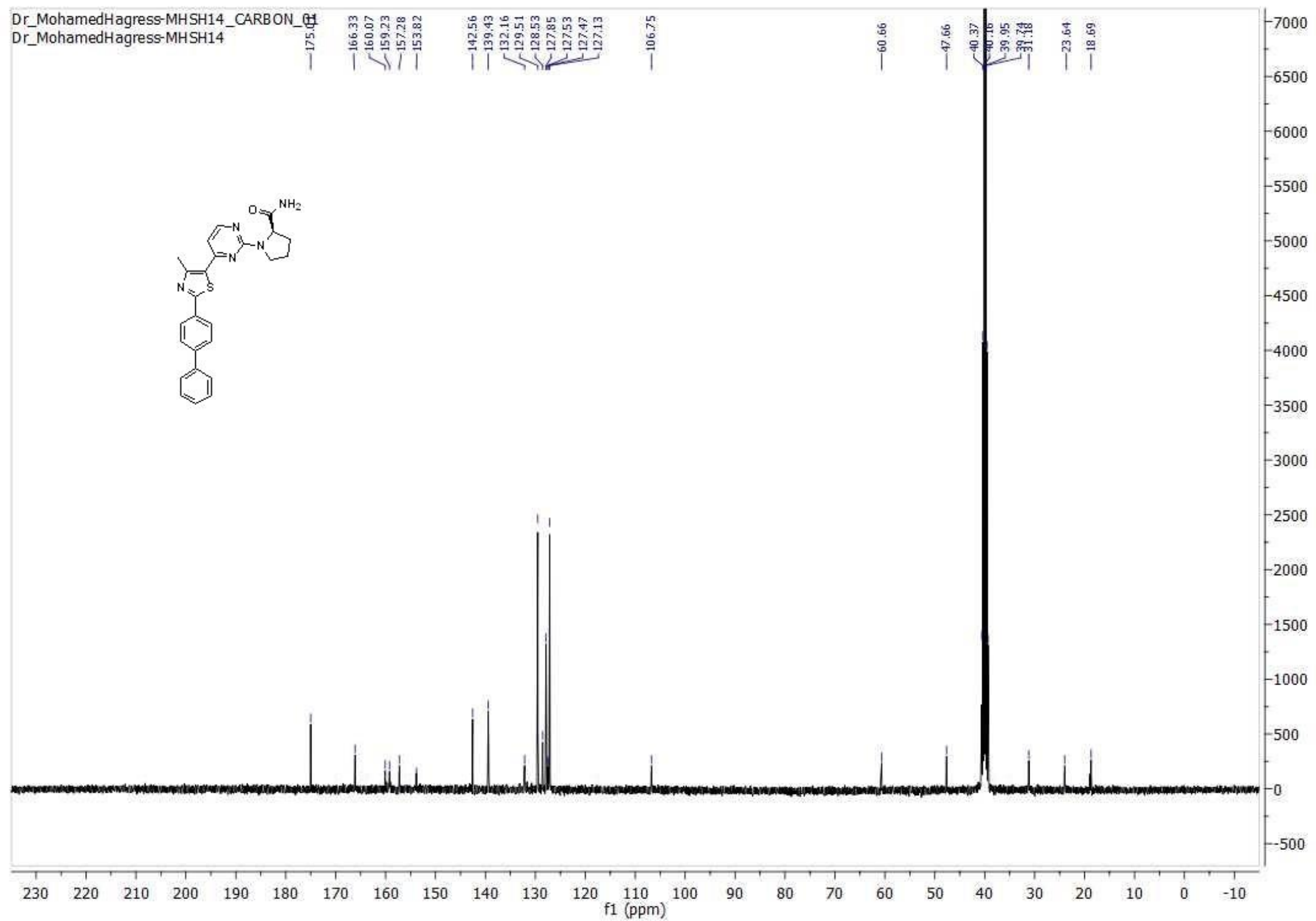




\section{References}

1. Hammad, A.; Abutaleb, N. S.; Elsebaei, M. M.; Norvil, A. B.; Alswah, M.; Ali, A. O.; Abdel-Aleem, J. A.; Alattar, A.; Bayoumi, S. A.; Gowher, H.; Seleem, M. N.; Mayhoub, A. S., From Phenylthiazoles to Phenylpyrazoles: Broadening the Antibacterial Spectrum toward Carbapenem-Resistant Bacteria. J Med Chem 2019, 62 (17), 7998-8010. DOI: 10.1021/acs.jmedchem.9b00720.

2. CLSI, Methods for Dilution Antimicrobial Susceptibility Tests for Bacteria That Grow Aerobically; Approved Standard. January 2012; Vol. Ninth Edition M07-A9. 32 No. 2.

3. Elsebaei, M. M.; Mohammad, H.; Abouf, M.; Abutaleb, N. S.; Hegazy, Y. A.; Ghiaty, A.; Chen, L.; Zhang, J.; Malwal, S. R.; Oldfield, E.; Seleem, M. N.; Mayhoub, A. S., Alkynylcontaining phenylthiazoles: Systemically active antibacterial agents effective against methicillinresistant Staphylococcus aureus (MRSA). Eur J Med Chem 2018, 148, 195-209. DOI: 10.1016/j.ejmech.2018.02.031. 